\title{
Una experiencia de trabajo en equipo con soporte documental para la formación de competencias en Contabilidad Financiera
}

\section{An experience of team working using real documents for competence development in financial accounting}

\author{
Raquel Flórez López (rflorez@upo.es) \\ Esther Albelda Pérez (ealbper@upo.es) \\ Universidad Pablo de Olavide de Sevilla (España) \\ http://dx.doi.org/10.12795/EDUCADE.2012.i03.05
}

RESUMEN: El Espacio Europeo de Educación Superior (EEES) incide en la implicación activa del estudiante en la adquisición del conocimiento, por lo que promueve metodologías que faciliten el aprendizaje autónomo y el desarrollo de competencias vinculadas al ejercicio profesional. Esta necesidad, junto con la voluntad de incrementar la motivación del alumnado en el aprendizaje de la Contabilidad Financiera, determinó el desarrollo de la experiencia de innovación docente que se describe en este trabajo.

A partir del método docente del trabajo en equipo, complementado con tutorías obligatorias y la utilización de recursos informáticos, se ha planteado una metodología de aprendizaje centrada en el registro contable y la elaboración de información financiera a partir de documentación administrativa real. Mediante la aplicación de esta experiencia, se ha perseguido favorecer una mayor implicación del alumno en el proceso de aprendizaje y fomentar el desarrollo de competencias generales y específicas necesarias en la formación de los futuros profesionales contables.

Esta experiencia de innovación docente ha puesto de manifiesto que esta metodología activa de aprendizaje es mayoritariamente aceptada por los estudiantes, incrementa su motivación respecto al seguimiento continuado de la asignatura, y mejora las calificaciones obtenidas en las pruebas tradicionales de evaluación, lo que sugiere su idoneidad para su implantación en los estudios de Grado en el ámbito del EEES.

PALABRAS CLAVE: Aprendizaje activo, competencias, trabajo en equipo, documentación administrativo-contable, Contabilidad Financiera.

ABSTRACT: The European Higher Education Area (EHEA) focuses on the active involvement of students in the acquisition of knowledge, which promotes methods to facilitate self-learning and the development of professional skills. This objective, coupled with the desire to increase student motivation in learning financial accounting, led to the development of the teaching experience described in this paper.

Using the teaching method of teamwork, completed with obligatory tutorials and use of computing resources, a learning methodology was developed focused on bookkeeping from real documents. The implementation of this experience has pursued to promote greater student involvement in the learning process and encourage the development of general and specific skills needed in the training of future accounting professionals.

This experience has shown that this active learning methodology was largely accepted by the students, what facilitated their continuous monitoring of the subject and improved their grades. It suggests its suitability for implementation in new bachelor degrees such as Finance and Accounting or Business Administration.

KEYWORDS: Active learning skills, teamwork, real documents, Financial Accounting.

Artículo. Recibido: 25-5-2011 - Versiones revisadas: 20-01-2012, 25-05-2012, Aceptado: 11-06-2012

Licencia Creative Commons BY NC ND · 2012 · Asociación Española de Contabilidad y Administración de Empresas - AECA 


\section{INTRODUCCIÓN}

El marco del Espacio Europeo de Educación Superior pone especial énfasis en el aprendizaje activo, es decir, se pretende implicar al alumno como sujeto activo de su propia formación, preparándole para afrontar con éxito los retos que plantea el nuevo escenario de la educación universitaria, entre los que destacan (CIDUA, 2005; Rodríguez Espinar, 2004):

- La educación a lo largo de la vida como un imperativo social que va a permitir al individuo una construcción continuada de sus conocimientos y competencias.

- La necesidad de la actualización de conocimientos profesionales en un mundo en constante transformación.

- La versatilidad laboral y la necesidad de una mayor formación ante el aumento de la rotación de los períodos de trabajo y de formación.

Por ello, en los estudios de Grado se hace necesaria una renovación de los procesos enseñanza-aprendizaje a través de la implantación de metodologías docentes que favorezcan la implicación del alumno en el proceso de enseñanza-aprendizaje, fomenten el desarrollo de competencias y faciliten la interacción profesor-alumno (MEC, 2006a). Con este marco de referencia, se desarrolló la experiencia de innovación docente que se describe en este trabajo, realizada en el ámbito de la asignatura de Contabilidad Financiera.

Dada la importancia de la documentación administrativa como soporte informativo de las operaciones registradas por la Contabilidad Financiera, es recomendable que el alumno aprenda a localizar, interpretar y analizar los principales documentos administrativos en este ámbito. Por otra parte, el gestor contable se aleja cada vez más del rol individualista de hace décadas, para integrarse en equipos de trabajo integrados por especialistas que colaboran en la toma de decisiones empresariales.

A partir de estas reflexiones, se diseñó una experiencia de innovación docente basada en la utilización del trabajo en equipo, complementado con tutorías obligatorias y el empleo de recursos informáticos, para el registro contable y la elaboración de información financiera a partir de documentación administrativa real. Los objetivos perseguidos con esta experiencia fueron: (1) incrementar la implicación de los alumnos en el proceso de aprendizaje; (2) facilitar el desarrollo de competencias específicas comprensión y dominio de los conceptos básicos y la técnica contable, y habilidades para el manejo de la documentación administrativa inherente a la práctica profesional y el diseño de sistemas contables para su registro-; y (3) fomentar el desarrollo de determinadas competencias genéricas necesarias en la formación de los futuros profesionales en el ámbito contable -tales como la capacidad de comunicación oral y escrita, de trabajo en equipo, y de resolución de problemas-.

Esta experiencia se puso en práctica durante el segundo cuatrimestre de la asignatura de Contabilidad Financiera de primer curso de la Diplomatura en Ciencias Empresariales de la Universidad Pablo de Olavide de Sevilla. Los resultados obtenidos se han medido en términos de la implicación del alumnado hacia la asignatura (porcentaje de presentación a las pruebas de evaluación) y de los resultados obtenidos por los alumnos o evidencias de aprendizaje (porcentaje de aprobados en relación con las competencias específicas desarrolladas en las pruebas de evaluación). Con respecto al tercer objetivo, relacionado con el fomento de determinadas competencias genéricas, tanto alumnos como profesores coincidieron en señalar en mayor o menor medida que los resultados habían sido satisfactorios, si bien los datos obtenidos no permitieron medir de forma explícita el logro de este objetivo. 
El resto del trabajo se organiza como sigue. En el siguiente apartado se analizan las competencias a desarrollar a través de la experiencia propuesta, que han determinado su diseño y estructura, así como los métodos docentes utilizados. A continuación, se describe la experiencia desarrollada-objetivos, fases, material de apoyo propuesto, organización docente y normas de evaluación- y se analizan los resultados obtenidos, considerando las características propias del alumno y la evolución del aprendizaje a lo largo del curso. Finalmente, se señalan las principales conclusiones obtenidas y se plantean sugerencias para su implantación en los nuevos estudios de Grado.

\section{EL APRENDIZAJE ACTIVO EN CONTABILIDAD FINANCIERA}

\subsection{El APRENDIZAJE ACtivo PARA El DESARROLLO dE COMPETENCIAS CONTABLES}

El Espacio Europeo de Educación Superior supone el establecimiento de nuevos modelos curriculares en los que el aprendizaje del alumno no sólo se centra en la adquisición de conocimientos, tanto generales como específicos, sino también en destrezas, actitudes y valores. Como señala el informe CIDUA (2005), el objetivo de los nuevos planes de estudios será el preparar ciudadanos dotados de capacidades y habilidades que los cualifiquen para el ejercicio profesional competente demandado por la sociedad actual. Por ello, en el marco del Espacio Europeo de Educación Superior, la organización de las enseñanzas está basada en la adquisición de competencias por parte de los estudiantes, es decir, en proporcionar una formación adecuada para preparar ciudadanos cualificados profesionalmente. Este modelo de aprendizaje por competencias obedece tanto a la necesidad de comparabilidad, competitividad y transparencia de la educación superior, como para facilitar la movilidad de estudiantes y titulados universitarios en la Unión Europea.

Si bien el término competencias ha sido definido e interpretado de numerosas maneras y desde ámbitos dispares, Lasnier (2000) es uno de los autores más utilizados para referirse a las competencias, definidas como saber hacer complejo, resultado de la integración, movilización y adecuación de conocimientos, capacidades y habilidades utilizados eficazmente en situaciones diversas. Por lo tanto, las competencias pueden entenderse como el conjunto de conocimientos, capacidades, habilidades, actitudes y destrezas adquiridas, que dan lugar a un buen nivel de desarrollo y actuación personal y profesional. Partiendo de este matiz claramente relacionado con el perfil profesional, el Ministerio de Educación y Ciencia (2006b), en su documento de trabajo sobre directrices para la elaboración de títulos universitarios, utiliza el término competencia exclusivamente en su acepción académica, definiéndolas como una combinación de conocimientos, habilidades (intelectuales, manuales, sociales, etc.), actitudes y valores que capacitarán a un titulado para afrontar con garantías la resolución de problemas o la intervención en un asunto en un contexto académico, profesional o social determinado (MEC, 2006b, punto 15). En definitiva, las competencias se refieren a una combinación de atributos que describen el nivel de capacitación o cualificación de un titulado.

Una de las razones del Proyecto Tuning fue el deseo de contribuir a la creación del Espacio Europeo de Educación Superior, a través del consenso entre diferentes universidades europeas sobre puntos de referencia comunes basados en perfiles profesionales, resultados de aprendizaje, competencias, habilidades y destrezas (González y Wagenaar, 2003). Con relación a las competencias, el proyecto Tuning distingue entre competencias genéricas y competencias específicas. Las competencias genéricas, que pueden ser comunes a cualquier titulación, se dividen a su vez en (i) competencias sistémicas, relacionadas con la comprensión de la totalidad de un sistema o conjunto; (ii) competencias personales, vinculadas con las 
habilidades de interrelación social; y (iii) competencias instrumentales, relacionadas con el desarrollo de técnicas y medios para conseguir un determinado fin. Por su parte, las competencias específicas están vinculadas a los conocimientos y destrezas particulares de cada área temática o disciplina.

Centrándonos en la titulación en Administración y Dirección de Empresas, el Libro Blanco sobre los Estudios de Grado en Economía y en Empresa (CONFEDE, 2005) señala los diferentes perfiles profesionales relacionados con estas titulaciones y propone el conjunto de competencias específicas y genéricas a desarrollar por los futuros estudiantes de grado. En concreto, hace referencia a competencias genéricas tales como la capacidad para la resolución de problemas, capacidad de análisis y síntesis, habilidad para analizar y buscar información proveniente de fuentes diversas, capacidad para tomar decisiones, compromiso ético en el trabajo, capacidad para trabajar en equipo y capacidad de adaptación a nuevas situaciones.

Fuera del contexto académico, y en relación con la profesión contable, diversos organismos profesionales internacionales se han referido a las capacidades, habilidades o competencias necesarias para el ejercicio de la profesión (véase Escobar Pérez y Jiménez Cardoso, 2009). Así, las definiciones incluidas en los Internacional Education Standards (IFAC, 2008) incluyen el término "habilidades a desarrollar", distinguiéndolas de las competencias profesionales; sin embargo, en otros marcos internacionales se utiliza de forma indistinta tanto el término capacidades como competencias o habilidades.

Dada la diversidad de términos utilizada en estos pronunciamientos, en este trabajo se ha optado por utilizar el término competencias referido en el ámbito de la CONFEDE (2005) y del proyecto Tuning europeo, dado que es un término más amplio y constituye la referencia utilizada en los títulos de grado, tal y como se ha aclarado anteriormente.

En consecuencia, la finalidad de esta experiencia docente estaba dirigida a desarrollar determinadas competencias necesarias para la formación de futuros profesionales en el ámbito contable. Para ello, teniendo en cuenta los distintos marcos de referencia, tanto académicos como profesionales, señalados anteriormente, se consideraron tanto competencias de carácter general, como la capacidad de comunicación oral y escrita, de trabajo en equipo y de resolución de problemas (Arquero, 2000; Arquero, Donoso, Jiménez-Cardoso y González, 2009; Hassall y otros, 2005), como competencias específicas relacionadas directamente con la asignatura. La Tabla 1 resume las distintas competencias, definidas por el equipo docente, que se pretendían desarrollar con la experiencia planteada.

\subsection{LA SELECCIÓN DE METOdOLOGÍAS DE APRENDIZAJE ACTIVO}

A partir de la definición de las competencias a desarrollar, se establecieron las metodologías docentes a utilizar en la experiencia propuesta: el trabajo en equipo y las tutorías grupales. Asimismo, se consideró la conveniencia de emplear recursos informáticos y soportes documentales como facilitadores del aprendizaje activo.

\subsubsection{El trabajo en equipo}

La realización de trabajos en equipo permite al alumno profundizar en el conocimiento de los contenidos adquiridos en clase, aplicando éstos a la búsqueda de soluciones ante la aparición de nuevos problemas. Con este método, el alumno es el actor principal y el co-responsable de su aprendizaje, que se desarrolla mediante tres vías sucesivas: (i) al realizar el trabajo; (ii) al observar los errores cometidos y defender los puntos de vista que considera acertados; y (iii) al repasar el trabajo completo y corregido, y compararlo con su versión primitiva. 
TABLA 1. COMPETENCIAS A DESARROLlar CON LA EXPERIENCIA PROPUESTA

\begin{tabular}{|c|c|}
\hline \multicolumn{2}{|c|}{ TRABAJO EN EQUIPO CON SOPORTE DOCUMENTAL } \\
\hline COMPETENCIAS GENÉRICAS & $\begin{array}{l}\text { Sistémicas } \\
\text { (1) Capacidad de aprendizaje autónomo } \\
\text { Personales } \\
\text { (2) Capacidad para trabajar en equipo } \\
\text { Instrumentales } \\
\text { (3) Capacidad de localizar, organizar y utilizar la } \\
\text { información obtenida de múltiples fuentes } \\
\text { (4) Comunicación oral y escrita en castellano } \\
\text { (5) Capacidad para la resolución de problemas } \\
\text { (6) Capacidad de análisis y síntesis }\end{array}$ \\
\hline COMPETENCIAS ESPECÍFICAS & $\begin{array}{l}\text { (7) Dominio del lenguaje y terminología contable } \\
\text { (8) Comprensión de los conceptos fundamentales de la } \\
\text { Contabilidad } \\
\text { (9) Adquisición de habilidades para el desarrollo y } \\
\text { diseño de los instrumentos, herramientas y técnicas } \\
\text { contables básicas }\end{array}$ \\
\hline
\end{tabular}

Fuente: Elaboración propia

El desarrollo de trabajos puede suponer un adecuado complemento a las clases teóricas y prácticas, al transmitir al alumno no sólo conocimientos sino también posibilitar el desarrollo de habilidades y destrezas, puesto que:

- Fomenta el trabajo continuado y el autoaprendizaje.

- Acostumbra a los alumnos a manejar, seleccionar y trabajar con múltiples fuentes bibliográficas, bases de datos y documentos de soporte documental.

- Estimula la capacidad de síntesis y análisis de problemas, así como la estructuración de contenidos.

- Favorece el desarrollo de destrezas para el trabajo en equipo mediante la interacción del alumno con los demás componentes del grupo, lo que constituye un medio de socialización del individuo que facilita el desarrollo de distintas facetas morales y sociales.

- Potencia el desarrollo de los hábitos de auto-planificación y autocontrol de la acción.

- Favorece la comunicación, capacidad de síntesis y fluidez en el uso de conceptos y terminología contable, al tiempo que posibilita la participación de los demás alumnos a través del intercambio de opiniones.

A pesar de su idoneidad, la metodología del trabajo en equipo no está exenta de dificultades. Pueden surgir problemas relacionados con el grado de implicación de los componentes, la resistencia por parte de algunos alumnos, la falta de preparación para trabajar en grupo, o la aparición de comportamientos oportunistas (Ashraf, 2004; Hansen, 2006). Para tratar de evitar o minimizar estos problemas, el planteamiento del trabajo en equipo debía realizarse de forma que se garantizara la participación activa y equitativa de todos los componentes del grupo. Por ello, se dividió el trabajo en distintas áreas temáticas (operaciones de explotación, operaciones de inversión, operaciones de financiación, operaciones de cierre del ejercicio) y documentales 
(Libro Diario, Libro Mayor, Documentos Administrativos), facilitando el reparto del trabajo entre los distintos miembros del grupo, pero exigiendo la puesta en común y la integración de todas las partes.

En cualquier caso, para que el trabajo en equipo sea eficaz, el profesor debe realizar un seguimiento continuado de los progresos realizados por el grupo (Brooks y Ammons, 2003; McKendall, 2000; Young y Henquinet, 2000), por lo que es fundamental el establecimiento de tutorías periódicas.

\subsubsection{Las futorías grupales}

El proceso educativo no debe limitarse a la labor que realiza el profesor en el aula, sino que debe posibilitar la conversación individual entre docente y estudiante. Las tutorías constituyen técnicas docentes que fomentan el contacto del alumno con sus profesores, personalizando el proceso de aprendizaje. A efectos organizativos, puede distinguirse entre (i) tutoría individual, en la que se establece una relación directa entre profesor y estudiante sobre cuestiones académicas individuales o derivadas de su situación personal o profesional; y (ii) tutoría grupal, que se realiza con un grupo de alumnos, donde la tarea básica a desarrollar por el profesor es ser un buen conductor del grupo.

Para que la tutoría genere valor como instrumento de aprendizaje, el estudiante debe haber preparado previamente un tema para, con la ayuda del profesor, descubrir los aspectos no comprendidos adecuadamente, encaminándose hacia un mejor conocimiento de la materia, a la vez que se potencian sus capacidades. Por su parte, el profesor puede realizar un seguimiento individualizado del rendimiento de los alumnos, caracterizado por la participación activa de los estudiantes, el contacto directo alumno-profesor, el desarrollo del sentido crítico y la evaluación continua del estudiante (Gairín et al., 2004).

En el caso particular de la experiencia propuesta, se establecieron dos tutorías obligatorias con cada grupo. Estas tutorías grupales suponen un mecanismo de apoyo por parte del profesor a través del cual aporta retroalimentación continuada a los equipos, lo que les facilita el ajuste de su trabajo a los contenidos y competencias planteadas. En cada sesión, el equipo presenta al tutor el trabajo realizado hasta el momento, así como las dudas o problemas encontrados en su ejecución; el tutor analiza el trabajo presentado, realiza sugerencias de mejora y resuelve las cuestiones planteadas, llevando a cabo adicionalmente una tarea de apoyo y estímulo al equipo. De esta forma, se consigue una relación profesor-alumno más estrecha, potenciando el rol del docente como facilitador o guía del aprendizaje.

\subsubsection{Los recursos informáticos y la documentación de soporte instrumental}

El empleo de recursos informáticos en la enseñanza universitaria influye de manera significativa tanto en la forma de enseñar, como en la forma de aprender. Para el docente, los recursos informáticos facilitan el acceso inmediato a los contenidos, su organización y gestión, así como su presentación al alumno de forma flexible y atractiva. Entre los beneficios para el alumno derivados de la utilización de la informática en Contabilidad, Sánchez Tomás (1991) destaca que:

1. Acerca al alumno a la realidad operativa de la profesión contable, en la que el ordenador constituye un instrumento básico de la práctica diaria.

2. Libera al alumno de la realización de tareas rutinarias de registro para centrarse en la lógica de los problemas. 
3. Permite el pensamiento productivo basado en una comprensión de la naturaleza de los problemas y no en una mera memorización de reglas.

Igualmente, las redes de comunicaciones constituyen un recurso docente de primer orden que ha creado entornos propios de aprendizaje, y el desarrollo de nuevas vías de comunicación entre alumnos y profesores (correo electrónico, listas de distribución, - tutorías y campus virtuales), que favorecen la realización de trabajos en grupo (Zapata Ros, 1999). La experiencia propuesta se ha desarrollado utilizando el Campus Virtual de la Universidad, que ha servido como plataforma básica para (i) la distribución de la documentación inicial a los equipos de trabajo; (ii) el acceso a los contenidos básicos que sirven de base para la realización del trabajo; (iii) la comunicación asíncrona entre los miembros del equipo; (iv) la comunicación continua entre el equipo y el profesor, adicional a las tutorías obligatorias; y (v) la resolución de problemas y la aclaración de dudas generales.

Asimismo, el propio diseño de la experiencia consideraba la utilización de las tecnologías de la información (hoja de cálculo) como el instrumento básico de registro y gestión de la información contable a utilizar por los alumnos.

\section{DISEÑO DE UNA EXPERIENCIA DE TRABAJO EN EQUIPO CON SOPORTE DOCUMENTAL}

\subsection{OBJetIVOS}

De acuerdo con el análisis realizado sobre aprendizaje activo en el ámbito contable, la experiencia diseñada se articuló en torno a tres objetivos básicos:

1. Incrementar la implicación de los alumnos en el proceso de aprendizaje.

2. Facilitar el desarrollo de competencias específicas, tratando de afianzar el conocimiento y la comprensión de los conceptos básicos y la técnica contable relacionados con las operaciones más habituales de la práctica empresarial, así como el desarrollo de habilidades para el manejo de la documentación administrativa inherente a la práctica profesional y el diseño de sistemas contables para su registro.

3. Fomentar el desarrollo de determinadas competencias genéricas, definidas previamente por el equipo docente, necesarias en la formación de los futuros profesionales en el ámbito contable; estas competencias genéricas incluyen la capacidad de comunicación oral y escrita, de trabajo en equipo, y de resolución de problemas.

Si bien al diseñar la experiencia se definieron los tres objetivos enunciados anteriormente, solamente los dos primeros fueron testados empíricamente. El logro del tercer objetivo se comprobó de forma indirecta a través de las notas de las diferentes pruebas de evaluación, pero las competencias genéricas no pudieron ser objeto de medición explícita.

\subsection{Metodología}

Antes de describir la experiencia, es necesario comentar dos aspectos que deben tenerse en cuenta a la hora de interpretar los resultados obtenidos. En primer lugar, la asignatura Contabilidad Financiera era una asignatura anual de primer curso de la Diplomatura en Ciencias Empresariales. Al ser la primera asignatura del área de Economía Financiera y Contabilidad que el alumno abordaba en la titulación, implicaba que los alumnos no adquirían un nivel mínimo de conocimientos para 
enfrentarse al trabajo en grupo hasta la finalización del primer cuatrimestre. Esto puede provocar un sesgo muestral de autoselección (self selection bias, Heckman, 1979), pues los alumnos con más interés en la asignatura son los que decidirán participar, en relación con los resultados obtenidos en el primer cuatrimestre (calificaciones del primer parcial). De esta forma, los mejores estudiantes estarían sobre-representados en la experiencia respecto al grupo de no partícipes, lo que puede distorsionar los resultados obtenidos y requerirá el uso de técnicas de corrección.

Por otro lado, en el contexto anterior a la implantación de los Grados, el sistema de evaluación por excelencia era la realización de un examen final. Por ello, el trabajo en grupo se presentó como una actividad voluntaria y se propusieron dos sistemas alternativos de evaluación. El $80 \%$ de la nota final de la asignatura se superaba mediante exámenes teórico-prácticos parciales y/o un examen final. La realización del trabajo representaba el $20 \%$ de la nota final, no obstante al ser una actividad voluntaria, se sustituiría, para aquellos alumnos que no quisieran participar, por una prueba adicional, de similar contenido al trabajo propuesto (registro contable de operaciones a partir de una serie de documentos reales de carácter administrativocontable).

\subsubsection{Muestra}

La muestra utilizada estaba compuesta por 224 alumnos, una vez deducidos del total de matriculados los abandonos producidos durante el primer cuatrimestre. De la población de 224 alumnos, 141 (62,95\%) aceptaron participar en la experiencia, mientras que $83(37,05 \%)$ declinaron hacerlo. Para su realización se establecieron grupos de trabajo formados libremente por los estudiantes, que dispusieron de 15 días para comunicar su composición al profesor de prácticas. El número de grupos finalmente ascendió a 42, de entre 3 y 5 miembros, con una media de 3,36 alumnos por grupo.

Una vez formados los grupos de trabajo, se asignó un tutor a cada uno de ellos, encargado del seguimiento del grupo y su evaluación. Para evitar en lo posible la introducción de sesgos y garantizar la validez de los resultados, se evitó que los docentes encargados de impartir las clases teórico-prácticas tutorizaran a sus propios alumnos. Para cada uno de los 5 tutores implicados (dos de ellos a tiempo parcial), el número de grupos asignados osciló entre 5 y 14, según su disponibilidad (con una media de 10,5 trabajos/tutor). A cada tutor a tiempo completo se asignó en el Plan de Organización Docente 1,5 créditos (15 horas lectivas), al objeto de compensar su participación en la experiencia.

\subsubsection{Descripción y organización del trabajo}

El trabajo a desarrollar por los equipos se centró en el análisis documental y registro contable de las operaciones realizadas por una determinada empresa durante el tercer y cuarto trimestre de un ejercicio contable, utilizando para ello medios informáticos (hoja de cálculo). Para ello, se crearon dos empresas: OFISA, cuyo objeto social era la venta y reparación de equipos informáticos; y TRANSPORSUR, dedicada al transporte de mercancías no peligrosas por carretera (los nombres de ambas empresas son simulados).

El trabajo se dividió en dos partes, cuyo cronograma se recoge en el Anexo I (cuadro 1). En la primera parte, se proporcionó a cada grupo de trabajo el Balance de Sumas y Saldos de su empresa, a fecha 31 de julio, así como la información adicional necesaria 
para comprender el origen de las cuentas y saldos incluidos en el mismo (actividad, sede social, inventario del inmovilizado, situación laboral, política de cobros y pagos, financiación externa, obligaciones fiscales y sociales), acompañada de los correspondientes documentos justificativos. A partir de dicho Balance, se solicitó el registro contable de las operaciones realizadas por la entidad durante el tercer trimestre del ejercicio, relacionadas fundamentalmente con: (i) pasivos y activos financieros no comerciales; (ii) remuneración del personal asalariado; (iii) compras de existencias; (iv) servicios exteriores y otros gastos corrientes; (v) ingresos de explotación; (v) operaciones vinculadas con las obligaciones fiscales y sociales de la empresa (liquidaciones de IVA, retenciones del personal y seguridad social). Para cada una de estas operaciones se proporcionó únicamente el correspondiente documento administrativo o mercantil que la soportaba (Anexo I, cuadro 2). Si bien cada grupo disponía del mismo número de documentos a analizar, el paquete total era diferente por grupo. Para ello se formularon cuatro modelos distintos de cada documento que fueron combinados entre sí, lo que unido a las dos empresas analizadas generaron un número muy elevado de potenciales combinaciones de paquetes documentales, muy superior al número de grupos gestionados. Cada grupo debía analizar e interpretar cada documento y decidir la forma más adecuada de contabilización, soportada mediante hojas de cálculo (una hoja diferente para el libro Diario, libro Mayor, y Balances de Comprobación); justificar y explicar las operaciones contabilizadas; completar los modelos fiscales 110, 115, 303 y los modelos TC1 y TC2 correspondientes a la Seguridad Social; y elaborar el Balance de Sumas y Saldos resultante a fecha 30 de septiembre. La primera parte del trabajo debía realizarse en un periodo máximo de cinco semanas, y presentarse al tutor en la primera tutoría obligatoria. En dicha tutoría se resolvieron las dudas planteadas por cada grupo y los problemas surgidos en la elaboración del trabajo; asimismo, se llevó a cabo una primera corrección de las operaciones contabilizadas, con el objetivo de que el grupo realizase los cambios pertinentes para la correcta elaboración de la segunda parte del trabajo.

En la segunda parte del trabajo, a desarrollar en otras cinco semanas, se solicitaba a los alumnos la contabilización de las operaciones correspondientes al cuarto trimestre, la regularización y cierre del ejercicio, y la formulación del Balance de Sumas a Saldos a 31 de diciembre. Para ello, se proporcionó a cada grupo la correspondiente documentación, que incluía, además de las operaciones típicas del tráfico de la empresa, transacciones relacionadas con: (i) activos y pasivos financieros comerciales (con particular incidencia en los efectos comerciales); (ii) transacciones de inmovilizado; y (iii) operaciones al cierre (regularización de existencias, deterioros de valor, devengo de ingresos y gastos, devengo de impuestos, periodificaciones, amortizaciones). Asimismo, se informaba sobre cambios en la política de cobros y pagos, y una serie de ajustes excepcionales debido a la situación de crisis económica (despido de trabajadores, búsqueda de fuentes de financiación alternativas, cancelación de contratos de servicios exteriores). Al igual que en la primera parte, se requirió la contabilización de las operaciones utilizando las correspondientes hojas de cálculo, su justificación razonada, y la elaboración de los modelos fiscales $(110,115$, 202,303 ) y sociales (TC1, TC2) correspondientes. La segunda parte del trabajo se presentó al tutor en la segunda tutoría obligatoria, acompañada por las oportunas correcciones de los errores detectados en la primera tutoría. De nuevo, el tutor resolvió las dudas presentadas y realizó una revisión de las soluciones aportadas, sugiriendo las mejoras oportunas.

Cada grupo dispuso de una semana adicional para cerrar el trabajo, sin admitirse demoras de ningún tipo. La presentación final del trabajo incluía la solución de las operaciones de los trimestres tercero y cuarto (Libro Diario, Libro Mayor, Balances de Comprobación de Sumas y Saldos, documentos fiscales y sociales completos), con 
referencias que facilitasen su localización (numeración de asientos, notas adicionales, etc.) y las oportunas justificaciones teóricas.

A partir de la planificación del trabajo del alumno, se llevo a cabo la programación del trabajo del profesor; teniendo en cuenta la media de 10,5 trabajos por tutor a tiempo completo, la carga docente asignada a cada tutor (1,5 créditos) se distribuyó como sigue:

1) Primera tutoría obligatoria: 5 horas (28,57 minutos/trabajo)

2) Segunda tutoría obligatoria: 5 horas (28,57 minutos/trabajo)

3) Evaluación y calificación de los trabajos: 5 horas (28,57 minutos/trabajo)

\subsubsection{Evaluación}

La experiencia desarrollada estuvo dirigida a que el alumno afianzara los conceptos relacionados con algunas de las operaciones más habituales en la práctica empresarial de manera autónoma. Por ello, se diseñó para que los alumnos trabajasen con documentación real, conociesen la problemática que puede originarse del manejo de dichos documentos, supieran reconocer los conceptos e información incluida en ellos, y comprendieran las normas aplicables para su correcta contabilización. Asimismo, la experiencia exigía que los alumnos diseñasen un sistema básico de registro contable mediante hoja de cálculo, con el objetivo de que comprendiesen las relaciones entre los distintos libros y magnitudes contables y la utilidad de esta herramienta informática para gestionar la información de forma rápida y con un bajo coste. De esta forma, se pretendía que los alumnos aprendiesen mejor y de forma más eficaz la problemática contable empresarial, facilitando el aprendizaje de conocimientos, habilidades y actitudes que se les van a requerir en su futuro profesional en un entorno de trabajo en equipo.

En consecuencia, la evaluación del trabajo se realizó de forma continua durante el desarrollo de la experiencia, siendo objeto de evaluación no sólo el producto final entregado, sino aspectos adicionales como la participación en las tutorías o la cohesión del grupo, y el desarrollo de las competencias definidas. Dado el entorno de trabajo en equipo, la calificación obtenida fue la misma para todos los miembros del grupo. El Anexo I recoge la hoja de evaluación utilizada, en la que se detallan los criterios de evaluación, haciendo referencia a las competencias desarrolladas, y organizados en torno a tres bloques principales: (i) planteamiento del trabajo en la primera tutoría; (ii) seguimiento del trabajo en la segunda tutoría; y (iii) evaluación del trabajo final.

\subsection{Resultados desde la perspectiva del alumno. AnÁlisis descriptivo}

El éxito vinculado a la realización de la experiencia se ha analizado a partir de cinco variables fundamentales: (i) porcentaje de alumnos que decidieron participar; (ii) tasa de superación (trabajos con una calificación igual o superior a 5 puntos sobre 10); (iii) nota media de los trabajos; (iv) nota media de los trabajos superados; y (v) nota media de los trabajos no superados. La Tabla 2 resume los principales resultados obtenidos con la experiencia desde el punto de vista del alumno.

La participación en la experiencia alcanzó el $62,95 \%$ de la población, y la nota media de los trabajos superó el aprobado (6,025 puntos sobre 10). En particular, el $80,85 \%$ de los alumnos participantes aprobó el trabajo, con una calificación media de 6,840 
puntos, lo que resulta indicativo de la calidad de los resultados y el esfuerzo invertido por los estudiantes.

TAbla 2. Realización de la eXPeriencia (PRINCIPAles descriptivos)

\begin{tabular}{|l|c|c|}
\hline & Media & Desviación estándar \\
\hline Porcentaje de participación en la experiencia & $(141 / 224)$ & - \\
\hline Tasa de superación de la experiencia & $62,95 \%$ & \\
\hline Nota media (d.s) de los trabajos & $(114 / 141)$ & - \\
\hline Nota media (d.s) de los trabajos superados (0 a 10) & $80,85 \%$ & \\
\hline Nota media (d.s) de los trabajos no superados (0 a 10) & 6,025 & 2,322 \\
\hline
\end{tabular}

A partir de estos resultados, se analizó la posible relación entre la participación en la experiencia y las calificaciones de los alumnos en las pruebas tradicionales de evaluación' (exámenes), distinguiendo dos momentos de tiempo: (a) inicio de la experiencia y (b) finalización de la experiencia.

\subsubsection{Resultados al inicio de la experiencia}

Por lo que respecta al inicio de la experiencia, el estudio se ha centrado en la relación entre las calificaciones obtenidas por los alumnos en el primer parcial (previo al trabajo en grupo) y la decisión de participar en la experiencia, distinguiendo entre: (1) los alumnos presentados que aprobaron el primer parcial; (2) los alumnos presentados que no aprobaron el primer parcial; y (3) los alumnos que no se presentaron al primer parcial.

La Tabla 3 resume los principales resultados obtenidos, incluyendo la prueba ANOVA de igualdad de medias para cada conjunto de alumnos que superó o no el primer parcial y su detalle por grupos de calificaciones (aprobado y suspenso).

Los resultados obtenidos permiten observar que la mayoría de los alumnos que participaron en la experiencia habían aprobado el primer parcial $(53,90 \%)$ mientras que el $71,08 \%$ de los estudiantes que no participaron había suspendido dicha evaluación. Las diferencias en las calificaciones de cada conjunto de alumnos resultan estadísticamente significativas (test ANOVA de igualdad de medias), lo que refuerza la existencia de sesgo de autoselección en la muestra. Asimismo, las notas numéricas entre el grupo de partícipes y no partícipes difieren entre sí (ANOVA $p=0,000$ ): los alumnos aprobados incluidos en la experiencia alcanzan un 6,81 frente al 6,29 de los no participantes (diferencia no significativa); $y$, la nota media de los alumnos suspensos es superior en el grupo de participantes $(3,14)$ frente a los no partícipes $(2,25)$ (diferencia significativa al 95\%).

1 El contenido de las pruebas tradicionales de evaluación está diseñado en torno a las competencias específicas de la asignatura; este tipo de exámenes sigue un diseño múltiple, incluyendo pruebas que miden la capacidad del alumno para discriminar y reflexionar entre distintos conceptos y términos contables (p.e. gasto, ingreso, activo, pasivo, instrumento financiero); y pruebas que miden la capacidad del alumno para registrar adecuadamente las principales operaciones contables (contabilización de uno o varios supuestos prácticos próximos a la realidad). 
TABLA 3. DesCRIPTIVOS DE LOS RESULTADOS, PRIMER PARCIAL (\%)

\begin{tabular}{|c|c|c|c|c|}
\hline \multicolumn{2}{|c|}{ Calificación primer parcial } & $\begin{array}{c}\text { Total con/sin } \\
\text { trabajo (\%) }\end{array}$ & $\begin{array}{c}\text { Total por } \\
\text { calificación (\%) }\end{array}$ & $\begin{array}{l}\text { Nota media por } \\
\text { calificación (d.e.) }\end{array}$ \\
\hline \multirow{4}{*}{$\begin{array}{l}\text { Con } \\
\text { trabajo } \\
\text { en grupo }\end{array}$} & Aprobados (A) & $76(53,90 \%)$ & $76(89,41 \%)$ & $6,81(1,06)$ \\
\hline & Suspensos (S) & $55(39,01 \%)$ & $55(48,25 \%)$ & $3,14(1,18)$ \\
\hline & No presentados (NP) & $10(7,09 \%)$ & $10(40,00 \%)$ & - \\
\hline & TOTAL & $141(100 \%)$ & $141(-)$ & $5,25(2,12)$ \\
\hline \multirow{4}{*}{$\begin{array}{l}\text { Sin } \\
\text { trabajo } \\
\text { en grupo }\end{array}$} & Aprobados (A) & $9(10,84 \%)$ & $9(10,59 \%)$ & $6,29(1,32)$ \\
\hline & Suspensos (S) & $59(71,08 \%)$ & $59(51,75 \%)$ & $2,25(1,76)$ \\
\hline & No presentados (NP) & $15(18,07 \%)$ & $15(60,00 \%)$ & - \\
\hline & TOTAL & $83(100 \%)$ & $83(-)$ & $2,50(2,07)$ \\
\hline \multicolumn{2}{|l|}{ ANOVA $p$} & \multicolumn{2}{|c|}{0,000} & $\begin{array}{c}\text { Total: } 0,000 \\
\text { A: } 0,211 \\
\text { S: } 0,018\end{array}$ \\
\hline
\end{tabular}

Si se analizan los resultados por grupos de calificaciones, puede observarse una relación directa entre la calificación previa del alumno ("aprobado", "suspenso", "no presentado") y su decisión de participar o no en la experiencia. La experiencia interesó a casi el $90 \%$ de los alumnos que habían superado el primer parcial (los más comprometidos con la asignatura), frente al $48,25 \%$ de los suspensos, porcentaje que se reduce al $40 \%$ en el caso de los estudiantes no presentados a dicha prueba de evaluación. La explicación de este comportamiento hay que buscarla en el compromiso de los estudiantes: los alumnos con más interés en la asignatura obtienen mejores resultados en las pruebas de evaluación, y son más proclives a participar en experiencias docentes como la propuesta. A su vez, la propia calificación obtenida refuerza el compromiso del estudiante, para mejor o para peor, por lo que el docente debe prestar una especial atención al momento de realización de la experiencia (inicio, durante o final del curso), ya que constituye una variable explicativa esencial de los resultados obtenidos.

\subsubsection{Resultados a la finalización de la experiencia}

En una segunda etapa se han considerado las calificaciones del alumno tras participar en la experiencia, esto es, respecto al segundo parcial de la asignatura. Se ha distinguido de nuevo entre: (1) alumnos presentados y aprobados en el segundo parcial; (2) alumnos presentados y no aprobados en el segundo parcial; y (3) alumnos no presentados al segundo parcial. Asimismo se ha analizado la superación o no del trabajo en grupo, si bien esta variable fue conocida por el discente con posterioridad a la realización del segundo parcial.

Con el objetivo de controlar el sesgo de autoselección, se ha analizado la evolución de las calificaciones respecto al primer y segundo parcial para los partícipes y no partícipes en la experiencia (incremento o disminución porcentual de la nota obtenida). La Tabla 4 resume los principales resultados obtenidos.

Como puede observarse, existe una relación positiva entre la participación y el porcentaje de alumnos presentados y aprobados en el segundo parcial: el 100\% de los alumnos que aprobó el segundo parcial había participado en la experiencia, correspondiendo el $91,11 \%$ a estudiantes que habían superado el trabajo en grupo. Si 
bien la tasa de suspensos fue elevada para los alumnos que superaron el trabajo $(43,86 \%)$, resultó inferior que la tasa respectiva para los alumnos que no superaron la experiencia $(59,26 \%)$. Por último, el porcentaje de no presentados ascendió a tan sólo el $20,18 \%$ y $25,93 \%$ de los alumnos que realizaron el trabajo (superado éste o no, respectivamente), mientras que el $80,72 \%$ de los discentes sin trabajo decidieron no acudir a la prueba de evaluación. Estas diferencias en las calificaciones entre los alumnos que realizaron la experiencia es estadísticamente significativa (ANOVA $p=$ $0,000)$.

TABLA 4. Descriptivos de los resultados, SEgundo parcial (\%)

\begin{tabular}{|c|c|c|c|c|c|c|}
\hline \multicolumn{2}{|c|}{ Realización del trabajo } & $\begin{array}{l}\text { Convocatoria del } \\
\text { segundo parcial }\end{array}$ & $\begin{array}{c}\text { Total } \\
\text { con/sin } \\
\text { trabajo (\%) }\end{array}$ & $\begin{array}{c}\text { Total por } \\
\text { calificación } \\
(\%)\end{array}$ & $\begin{array}{l}\text { Nota } \\
\text { media* }\end{array}$ & $\begin{array}{c}\text { Variación } \\
\text { de la } \\
\text { nota** }^{* *}\end{array}$ \\
\hline \multirow{8}{*}{$\begin{array}{l}\text { Con } \\
\text { trabajo en } \\
\text { grupo (CT) }\end{array}$} & \multirow{4}{*}{$\begin{array}{l}\text { Superado } \\
\text { (CTS) }\end{array}$} & Aprobados & $41(35,96 \%)$ & $41(91,11 \%)$ & $\begin{array}{c}6,16 \\
(1,09)\end{array}$ & \multirow{4}{*}{$-30,04 \%$} \\
\hline & & Suspensos & $50(43,86 \%)$ & $50(60,98 \%)$ & $\begin{array}{c}2,37 \\
(1,21)\end{array}$ & \\
\hline & & No presentados & $23(20,18 \%)$ & $23(23,71 \%)$ & - & \\
\hline & & TOTAL & $\begin{array}{c}114 \\
(100,00 \%) \\
\end{array}$ & $114(-)$ & $\begin{array}{c}4,08 \\
(2,22)\end{array}$ & \\
\hline & \multirow{4}{*}{$\begin{array}{c}\text { no } \\
\text { superado } \\
\text { (CTNS) }\end{array}$} & Aprobados & $4(14,81 \%)$ & $4(8,89 \%)$ & $\begin{array}{c}5,71 \\
(0,56)\end{array}$ & \multirow{4}{*}{$-36,17 \%$} \\
\hline & & Suspensos & $16(59,26 \%)$ & $16(19,51 \%)$ & $\begin{array}{c}2,73 \\
(1,55)\end{array}$ & \\
\hline & & No presentados & $7(25,93 \%)$ & $7(7,22 \%)$ & - & \\
\hline & & TOTAL & $27(100,00 \%)$ & $27(-)$ & $\begin{array}{c}3,32 \\
(1,86)\end{array}$ & \\
\hline \multirow{4}{*}{\multicolumn{2}{|c|}{ Sin trabajo en grupo (ST) }} & Aprobados & $0(0,00 \%)$ & $0(0,00 \%)$ & - & \multirow{4}{*}{$-44,04 \%$} \\
\hline & & Suspensos & $16(19,28 \%)$ & $16(19,51 \%)$ & $\begin{array}{c}1,49 \\
(1,31)\end{array}$ & \\
\hline & & No presentados & $67(80,72 \%)$ & $67(69,07 \%)$ & - & \\
\hline & & TOTAL & $83(100,00 \%)$ & $83(-)$ & $\begin{array}{c}1,49 \\
(1,31) \\
\end{array}$ & \\
\hline \multicolumn{3}{|c|}{ ANOVA $p$} & \multicolumn{2}{|c|}{$\begin{array}{c}0,000 \\
\text { (inter calificaciones) }\end{array}$} & $\begin{array}{c}\text { Total: } \\
0,000 \\
\text { A: } 0,420 \\
\text { S: } 0,023\end{array}$ & $\begin{array}{c}0,09 \\
\text { (CT vs. ST) }\end{array}$ \\
\hline
\end{tabular}

Con trabajo en grupo superado (CTS), Con trabajo en grupo no superado (CTNS)

** Nota media por calificación (d.e.)

* Variación de la nota respecto al primer parcial (sobre presentados)

Si se comparan los datos obtenidos a posteriori (segundo parcial) con los datos a priori (primer parcial), se observan diferencias significativas entre las que destacan (Figura 1):

1. El número de aprobados ha disminuido significativamente respecto al primer parcial de la asignatura (45 vs. 86 alumnos), si bien en cifras relativas se ha incrementado respecto a los alumnos que realizaron la experiencia $(100,00 \% \mathrm{vs}$. 89,53\%). Esta reducción en la calificación de la segunda prueba es habitual en la asignatura, al destinarse el primer parcial a proporcionar al alumno los conceptos contables básicos (Marco Conceptual y Teoría Contable, principalmente), dedicándose el segundo parcial al desarrollo del Proceso Contable completo, lo que incrementa su complejidad. 
2. El número de suspensos se ha reducido respecto al primer parcial de la asignatura (82 vs. 114), si bien se ha incrementado significativamente el número de alumnos no presentados (97 vs. 25) que se concentraron mayoritariamente en alumnos no implicados en la experiencia $(69,07 \%)$.

Asimismo, existen diferencias en la evolución de la nota numérica del alumno que participa o no en la experiencia. Aquellos que superan el trabajo en grupo obtienen una nota media inferior en un 30,04\% al primer parcial; los que no superan el trabajo ven disminuida su nota del segundo parcial en un $36,17 \%$; y los que no participan en la experiencia reducen su calificación en más de un 44\%. Estas diferencias son estadísticamente significativas según el test de ANOVA $(p<0.1)$; si bien el grado de confianza se reduce al 91\%, este resultado justifica la validez de la experiencia realizada, una vez controladas las distorsiones producidas por el sesgo de autoselección. De esta forma, puede concluirse que, si bien la mayor dificultad de los contenidos impartidos se ha reflejado en las calificaciones finales del alumno, la realización del trabajo ha influido en la menor reducción de la nota obtenida (particularmente si el trabajo se superaba), lo que permite inferir un efecto positivo de la experiencia realizada.

Finalmente, la Tabla 5 resume la relación existente entre la participación en la experiencia (superado o no el trabajo en grupo) y la calificación final del alumno en la convocatoria de junio. Cabe comentar que en dicha convocatoria se permitió a los alumnos recuperar los parciales suspensos, así como mejorar su nota, en su caso. Por su parte, los alumnos suspensos en algún examen parcial pero no presentados al examen final de junio aparecerían en las actas finales como "no presentados".

TABLA 5. Descriptivos de los Resultados, NOtA finAl (\%)

\begin{tabular}{|c|c|c|c|c|c|}
\hline \multicolumn{2}{|c|}{ Calificación Junio } & $\begin{array}{l}\text { Convocatoria } \\
\text { de Junio }\end{array}$ & $\begin{array}{c}\text { Total } \\
\text { con/sin } \\
\text { trabajo (\%) }\end{array}$ & $\begin{array}{c}\text { Total por } \\
\text { calificación } \\
(\%)\end{array}$ & $\begin{array}{l}\text { Nota media por } \\
\text { calificación } \\
\text { (d.e.) }\end{array}$ \\
\hline \multirow{8}{*}{$\begin{array}{l}\text { Con } \\
\text { trabajo en } \\
\text { grupo (CT) }\end{array}$} & \multirow{4}{*}{$\begin{array}{l}\text { superado } \\
\text { (CTS) }\end{array}$} & Aprobados & $64(56,14 \%)$ & $64(80,00 \%)$ & $6,79(1,29)$ \\
\hline & & Suspensos & $8(7,02 \%)$ & $8(34,78 \%)$ & $2,75(0,93)$ \\
\hline & & $\begin{array}{c}\text { No } \\
\text { presentados }\end{array}$ & $42(36,84 \%)$ & $42(34,71 \%)$ & $=1$, \\
\hline & & TOTAL & $\begin{array}{c}114 \\
(100,00 \%) \\
\end{array}$ & $114(-)$ & $6,34(1,79)$ \\
\hline & \multirow{4}{*}{$\begin{array}{c}\text { no } \\
\text { superado } \\
\text { (CTNS) }\end{array}$} & Aprobados & $12(44,44 \%)$ & $12(15,00 \%)$ & $5,46(0,50)$ \\
\hline & & Suspensos & $9(33,33 \%)$ & $9(39,13 \%)$ & $2,59(0,69)$ \\
\hline & & $\begin{array}{c}\text { No } \\
\text { presentados }\end{array}$ & $6(22,22 \%)$ & $6(4,96 \%)$ & - \\
\hline & & TOTAL & $27(100,00 \%)$ & $27(-)$ & $4,23(1,56)$ \\
\hline \multirow{4}{*}{\multicolumn{2}{|c|}{ Sin trabajo en grupo (ST) }} & Aprobados & $4(4,82 \%)$ & $4(5,00 \%)$ & $6,13(1,65)$ \\
\hline & & Suspensos & $6(7,23 \%)$ & $6(26,09 \%)$ & $1,92(1,11)$ \\
\hline & & $\begin{array}{c}\text { No } \\
\text { presentados }\end{array}$ & $73(87,95 \%)$ & $73(60,73 \%)$ & 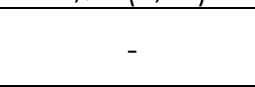 \\
\hline & & TOTAL & $83(100,00 \%)$ & $83(100,00 \%)$ & $3,60(2,51)$ \\
\hline \multicolumn{3}{|c|}{ ANOVA $p$} & \multicolumn{2}{|c|}{$\begin{array}{c}0,000 \\
\text { (inter calificaciones) }\end{array}$} & $\begin{array}{c}\text { Total: } 0,000 \\
\text { A: } 0,003 \\
\text { S: } 0,224\end{array}$ \\
\hline
\end{tabular}

Con trabajo en grupo superado (CTS), Con trabajo en grupo no superado (CTNS)

La nota final incluía, para los alumnos presentados, la nota media de ambos parciales (80\% del total) más la nota del trabajo en grupo (20\%) o, en su defecto, la nota obtenida en la prueba de calificación sustitutiva ofertada a los alumnos que 
decidieron no participar en la experiencia. Los resultados finales obtenidos apoyan los argumentos presentados a favor de una relación directa y positiva entre la participación en la experiencia y el compromiso de los estudiantes, reflejado en la presentación al examen y la superación de la asignatura (ANOVA $p=0.000$ ) (Figura 2). Así, sólo 4 alumnos no partícipes lograron superar la asignatura $(4,82 \%)$, mientras que el resto la suspendieron $(7,23 \%)$ o, mayoritariamente, decidieron no presentarse $(87,95 \%)$. En cambio, el $56,14 \%$ de los alumnos que participaron y superaron la experiencia aprobaron la asignatura, porcentaje que disminuyó ligeramente para aquéllos que no superaron el trabajo (44,44\%). Asimismo, la cifra de no presentados se redujo de forma muy significativa en el caso de los alumnos que realizaron el trabajo en grupo, con independencia de que éste estuviera superado $(36,84 \%)$ o no $(22,22 \%)$.

FigURA 1. EVOLUCIÓN EN LA DISTRIBUCIÓN DE CALIFICACIONES (PRIMER Y SEGUNDO PARCIAL)
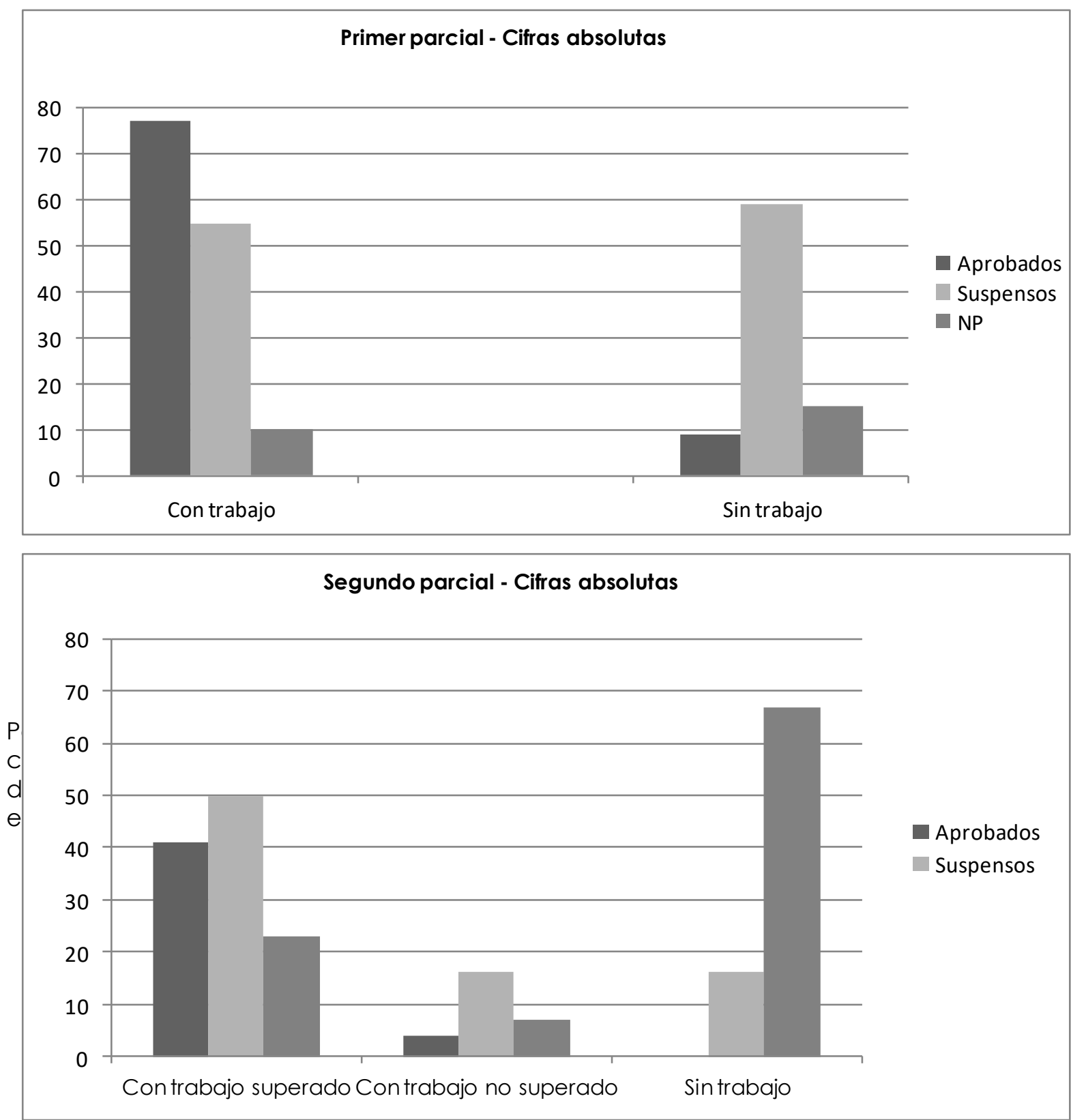
FigURA 2. EVOLUCIÓN EN LA DISTRIBUCIÓN DE CALIFICACIONES (NOTA FINAL)

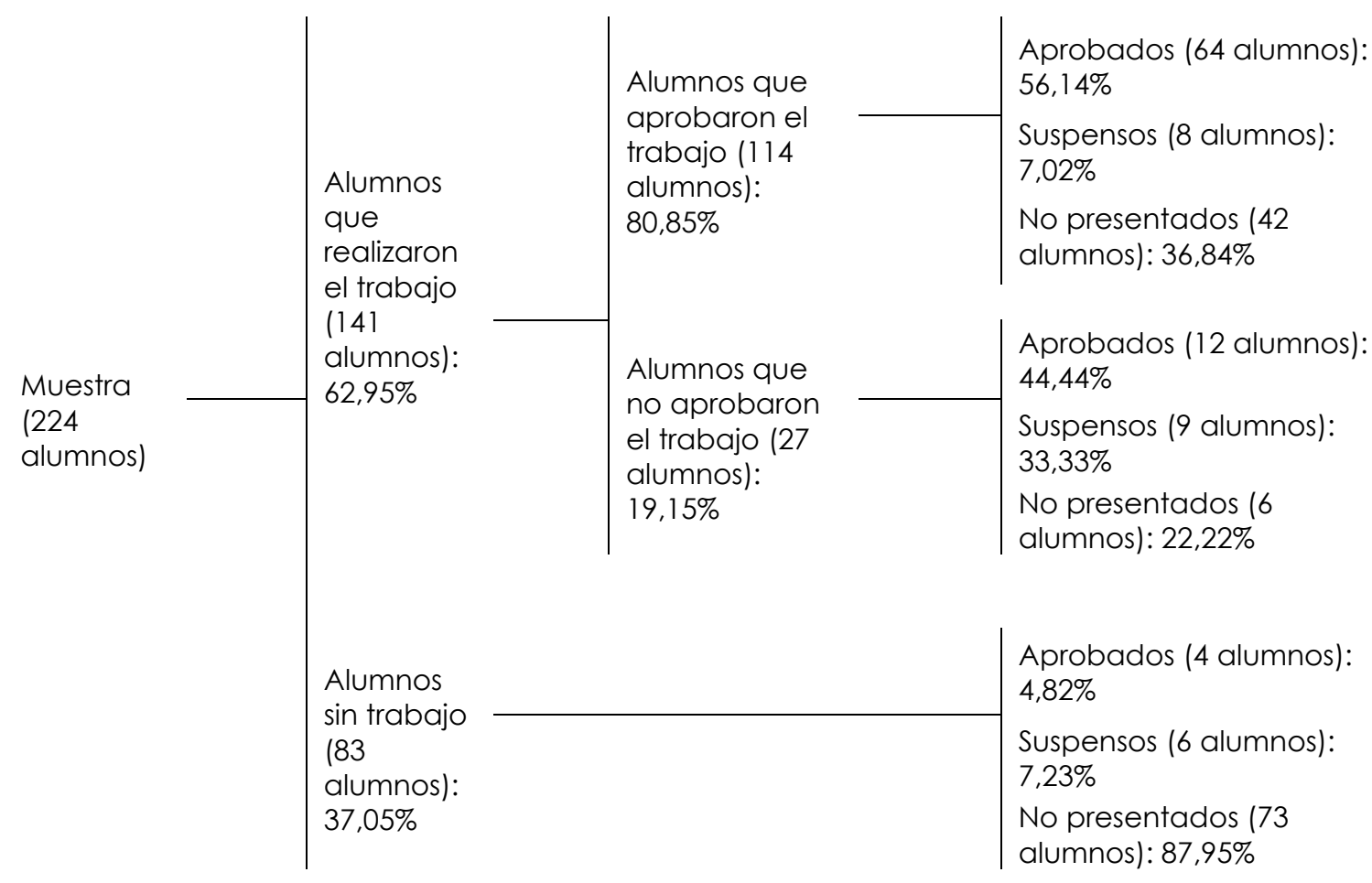

Finalmente, la comparación de los resultados finales con las cifras del primer y segundo parcial sugieren que la participación en la experiencia permitió al alumno preparar de forma más adecuada los contenidos suspensos respecto a las pruebas de recuperación, por encima del sesgo de autoselección. Así, 76 alumnos partícipes aprobaron la asignatura (el $84,21 \%$ de ellos habían superado el trabajo), frente a los 77 aprobados del primer parcial, y a los 45 del segundo parcial. Por el contrario, tan sólo 4 alumnos que no participaron en la experiencia aprobaron la convocatoria $(4,82 \%)$, porcentaje inferior a los 9 alumnos que habían superado el primer parcial (10,84\%).

\subsection{Resultados para el alumno. Análisis Causal}

El análisis descriptivo previo ha permitido formular una serie de hipótesis causales sobre los resultados obtenidos, antes y después de la realización de la experiencia. A continuación, se detallan y contrastan las distintas hipótesis, incluyendo dos variables de control adicionales, potencialmente explicativas de los resultados: (a) número de veces que se ha matriculado el alumno de la asignatura (MATR); y (b) número de convocatorias a las que se ha presentado el alumno (CONV).

\subsubsection{Resultados al inicio de la experiencia}

En primer lugar, se pretende analizar si la decisión de participar en la experiencia se vio influida por la superación o no del primer parcial de la asignatura. Como se ha comentado, el historial de calificaciones del alumno, representativo de su compromiso con la asignatura, puede afectar directamente a su predisposición a participar en trabajos prácticos como el presentado que, si bien se perciben como valiosos para el aprendizaje, precisan de un tiempo prolongado de realización que puede no compensar al alumno suspenso en evaluaciones previas, ya que percibe un alto riesgo 
de no superación de la asignatura. De esta forma, se ha establecido la siguiente hipótesis básica a contrastar:

H1: Existe una relación directa entre la superación o no del primer parcial y la decisión de participar en la experiencia.

Dado el carácter binario de la variable dependiente (1="participa", 0="no participa"), el contraste de hipótesis se ha realizado mediante un modelo de análisis discriminante lineal (ADL), considerando como variables explicativas la superación del primer parcial (2="superado", 1="suspenso" 0="no presentado") y las variables de control previamente definidas. Si bien el modelo ADL resulta adecuado para el estudio de variables categóricas, precisa el cumplimiento de un conjunto de hipótesis de partida, entre las que destacan:

- el numero de individuos debe ser igual o mayor que 2. Para la muestra analizada $\mathrm{N}=224$;

- $\quad$ ninguna variable independiente puede ser combinación lineal de otras. En el caso de la muestra analizada el coeficiente de correlación de Pearson entre las variables independientes toma un valor máximo de $0.532(<1)$, por lo que se verifica dicha hipótesis;

- las variables explicativas deben seguir una función normal multivariante. El Anexo II resume las pruebas de normalidad respecto a las distintas variables analizadas (prueba de Kolmogorov-Smirnov con corrección de Lilliefors y test de Shapiro-Wilks), pudiéndose observar el incumplimiento sistemático de esta hipótesis;

las matrices de varianza-covarianza de cada grupo deben ser aproximadamente iguales (hipótesis de homocedasticidad). El test de Levene realizado respecto a las variables independientes (Anexo II) permite observar el incumplimiento de esta hipótesis para dos de las tres variables analizadas.

A pesar del incumplimiento de las dos últimas hipótesis, el ADL es suficientemente robusto para tolerar ciertas desviaciones en los supuestos, máxime si las diferencias entre los grupos son significativas (Hair et al, 1999), como sugieren los estadísticos de la Tabla 3, por lo que cabe presumir un nivel de distorsión reducido respecto al modelo final.

La Tabla 6 resume los resultados finales obtenidos con el modelo de análisis discriminante. El modelo final obtenido es globalmente valido $\left(\mathrm{Chi}^{2} \mathrm{p}=0.000\right.$, Lambda de Wilks $>0,7)$, siendo capaz de predecir el $66,96 \%$ de las decisiones de los alumnos (frente al 53,48\% que se obtendría de forma aleatoria). Asimismo, el coeficiente de correlación cuadrática (CCC2) indica que el modelo explica el $16,8 \%$ de la varianza de la variable independiente.

Como puede observarse, existe una relación directa, positiva y significativa entre la superación del primer parcial de la asignatura y la decisión de participar en la experiencia (coeficiente estandarizado $=0,948$ ), siendo ésta la variable más explicativa, lo que confirma el riesgo de sesgo de autoselección previamente comentado. Asimismo, se contrastó que los alumnos que se habían matriculado más veces en la asignatura (coeficiente estandarizado=-0,090), y se habían presentado a más convocatorias (coeficiente estandarizado $=-0,138$ ) eran más reacios a realizar el trabajo en grupo, bien porque consideraban que el examen final implicaba menos esfuerzo para superar la asignatura al tiempo que constituía un método de evaluación seguro y experimentado, bien porque su nivel de motivación y compromiso era inferior al de los nuevos alumnos. 
TABLA 6. ANÁLISIS DISCRIMINANTE (INICIO DE LA EXPERIENCIA)

\begin{tabular}{|c|c|c|c|c|c|}
\hline \multirow{2}{*}{ Variable } & \multicolumn{2}{|c|}{ Coeficientes canónicos } & \multirow{2}{*}{$\begin{array}{l}\text { Carga discriminante } \\
\text { (valor absoluto) }\end{array}$} & \multicolumn{2}{|c|}{ Coeficientes lineales de Fisher } \\
\hline & $\begin{array}{c}\text { No } \\
\text { estandarizados }\end{array}$ & Estandarizados & & $\begin{array}{c}\text { Grupo } 1 \\
\text { (EXPPAR }=0)\end{array}$ & $\begin{array}{c}\text { Grupo 1 } \\
\text { (EXPPAR=1) }\end{array}$ \\
\hline 1PSUP & 1,593 & 0,948 & 0,980 & 3,133 & 4,608 \\
\hline MATR & $-0,061$ & $-0,090$ & 0,327 & 1,303 & 1,246 \\
\hline CONV & $-0,214$ & $-0,138$ & 0,296 & $-0,346$ & $-0,544$ \\
\hline Constante & $-1,850$ & & - & $-3,496$ & $-5,099$ \\
\hline \multicolumn{6}{|c|}{$\begin{array}{l}\text { Labmda de Wilks } 0,832 \\
\mathrm{Chi}^{2} \text { (p) } 40,537(0,000) \\
\mathrm{CCC}^{2} 0,168 \\
\text { Porcentaje correcto de clasificación (s.t.g) } 66,96 \% \\
\text { Criterio de aleatoriedad proporcional } 53,48 \%\end{array}$} \\
\hline
\end{tabular}

Con el fin de profundizar en la relación existente entre el primer parcial de la asignatura y la realización de la experiencia, se ha planteado una segunda hipótesis vinculada a las calificaciones numéricas obtenidas en el primer parcial por los 141 alumnos que participaron en el trabajo en grupo, como sigue:

H2: Existe una relación directa entre la calificación del alumno en el primer parcial y la calificación obtenida en el trabajo en grupo.

En este caso la variable dependiente está medida en escala de intervalo ( 0 a 10), lo que permite aplicar un modelo de regresión lineal para el contraste de hipótesis (Tabla 7). La regresión obtenida resulta estadísticamente significativa ( $F p=0,027)$, explicando un porcentaje moderado $(6,6 \%)$ de la varianza de la variable independiente.

TABLA 7. Regresión lineAL (INICIO de LA EXPERIENCIA)

\begin{tabular}{|l|r|r|r|r|r|}
\hline \multirow{2}{*}{ Variable } & \multicolumn{2}{|c|}{ Coeficientes no estandarizados } & \multirow{2}{*}{ Coeficientes estandarizados } & \multicolumn{2}{|c|}{ Prueba t } \\
\cline { 2 - 3 } & Beta & Error(Beta) & & Valor $\mathbf{~}$ & Signific. (p) \\
\hline 1PCAL & $\mathbf{0 , 2 0 0}$ & $\mathbf{0 , 0 7 3}$ & $\mathbf{0 , 2 3 1}$ & $\mathbf{2 , 7 5 1}$ & $\mathbf{0 , 0 0 7}$ \\
\hline MATR & $-0,075$ & 0,176 & $-0,041$ & $-0,425$ & 0,672 \\
\hline CONV & $-0,353$ & 0,413 & $-0,082$ & $-0,855$ & 0,394 \\
\hline Constante & 5,401 & 0,480 & & 11,246 & $0,000^{* *}$ \\
\hline$R^{2}\left(R^{2}\right.$ ajustada) 0,066 (0,045) \\
F (p) 3,150 (0,027) \\
Durbin Watson 1,082
\end{tabular}

Nota: * significativo al 95\% ( $p=0,05),{ }^{* *}$ significativo al 99\% $(p=0,01)$

Los resultados obtenidos proporcionan evidencia sobre la existencia de una relación positiva entre la nota numérica del alumno y la calificación final del trabajo ( $p=0.007$ ), lo que confirma que los conocimientos aprendidos durante el primer parcial resultaron básicos para la realización del trabajo en grupo.

\subsubsection{Resultados a la finalización de la experiencia}

El objetivo fundamental del trabajo en grupo era la adquisición de competencias vinculadas con la gestión y registro de las principales operaciones del ciclo contable de la empresa, lo que constituía la materia básica del segundo parcial de la asignatura. Un adecuado diseño y ejecución de la experiencia debía motivar al alumno a presentarse al segundo parcial (1="presentado", $0=$ "no presentado"), factor al que también contribuye la obtención de resultados positivos en el primer parcial. De esta forma, se formulan las siguientes hipótesis de trabajo: 
$\mathrm{H}_{31}$ : Existe una relación directa entre la superación o no del primer parcial y la decisión de presentarse al segundo parcial.

$\mathrm{H}_{32}$ : Existe una relación directa entre la participación o no en la experiencia y la decisión de presentarse al segundo parcial.

La Tabla 8 resume los resultados obtenidos mediante análisis discriminante, que resultan estadísticamente significativos en términos globales (Chi2 $\mathrm{p}=0,000 ; C C C 2=0,438$ ) y de validez en la clasificación (porcentaje correcto de clasificación del 79,9\% vs. $50,98 \%$ del criterio de aleatoriedad proporcional).

TABLA 8. ANÁlisis disCRIMINANTE (SEGUNDo PARCIAL)

\begin{tabular}{|c|c|c|c|c|c|}
\hline \multirow[t]{2}{*}{ Variable } & \multicolumn{2}{|c|}{ Coeficientes canonicos } & \multirow{2}{*}{$\begin{array}{c}\text { Carga } \\
\text { discriminante (valor } \\
\text { absoluto) }\end{array}$} & \multicolumn{2}{|c|}{$\begin{array}{c}\text { Coeficientes lineales de } \\
\text { Fisher }\end{array}$} \\
\hline & $\begin{array}{c}\text { No } \\
\text { estandarizados }\end{array}$ & Estandarizados & & $\begin{array}{c}\text { Grupo } 1 \\
(2 P P R E S=0)\end{array}$ & $\begin{array}{c}\text { Grupo } 1 \\
(2 \text { PPRES }=1)\end{array}$ \\
\hline 1PSUP & 1,068 & 0,601 & 0,804 & 3,400 & 5,298 \\
\hline EXPPAR & 1,920 & 0,759 & 0,654 & 1,982 & 5,393 \\
\hline MATR & 0,140 & 0,209 & 0,013 & 1,338 & 1,588 \\
\hline CONV & 0,156 & 0,102 & 0,012 & $-0,306$ & $-0,029$ \\
\hline Constante & $-2,867$ & & & $-3,761$ & $-8,643$ \\
\hline \multicolumn{6}{|c|}{$\begin{array}{l}\text { Labmda de Wilks: } 0,561 \\
\mathrm{Chi}^{2}(\mathrm{p}): 127,060(0,000) \\
\mathrm{CCC}^{2} 0,438 \\
\text { Porcentaje correcto de clasificación (s.t.g) } 79,9 \% \\
\text { Criterio de aleatoriedad proporcional } 50,98 \%\end{array}$} \\
\hline
\end{tabular}

Como puede observarse, la decisión de presentarse al segundo parcial de la asignatura se ve directa y positivamente afectada por la participación del alumno en la experiencia, que constituye la variable explicativa más significativa (carga discriminante $=0,804)$, y por la superación del primer parcial de la asignatura $(0,654)$. De esta forma, si bien existe un sesgo de autoselección (el alumno más comprometido en el primer parcial, y que por tanto lo ha superado, tiene más posibilidades de superar el segundo), la participación en la experiencia afecta positivamente al resultado por encima de dicho sesgo (el alumno que participe en la experiencia tiene más posibilidades de superar el segundo parcial, independientemente del resultado obtenido en la primera prueba).

En este caso, la influencia del número de matrículas y convocatorias a las que se ha presentado el alumno no resulta estadísticamente significativa (cargas discriminantes de 0,01 ), lo que indica que el efecto de estas variables se concentra en la decisión de participar en la experiencia y en la presentación al primer parcial, no existiendo efectos diferenciadores respecto al segundo parcial de la asignatura. Este dato resulta particularmente relevante, pues el papel del profesor como motivador del alumno resulta difícil y complejo cuando se acumulan suspensos a lo largo de cursos sucesivos.

Los resultados previos fueron analizados en detalle a través de las calificaciones numéricas obtenidas en el segundo parcial, con el objetivo de contrastar el siguiente conjunto de hipótesis:

$\mathrm{H}_{41}$ : Existe una relación directa entre la calificación del primer parcial y la calificación obtenida en el segundo parcial.

$\mathrm{H}_{42}$ : Existe una relación directa entre la participación o no en la experiencia y la calificación obtenida en el segundo parcial. 
Debido a la presencia de sesgo de autoselección, el contraste de las hipótesis se ha realizado mediante un modelo de Heckman en dos etapas (Heckman, 1979), basado en la estimación de dos ecuaciones simultáneas:

(1) la primera ecuación considera un modelo de regresión, siendo la variable dependiente la calificación obtenida en el segundo parcial (0-10), y como variables independientes la calificación del primer parcial y la participación en la experiencia.

(2) la segunda ecuación considera un modelo probit, siendo la variable dependiente la participación en la experiencia (1="participa", 0="no participa"), y como variables independientes la calificación del primer parcial, el número de veces que se ha matriculado el alumno (MATR) y el número de convocatorias a las que se ha presentado (CONV).

Al incorporar en la segunda ecuación variables que afectan a la participación en la experiencia pero que no tienen un efecto directo sobre las notas del segundo parcial, se aísla el sesgo de autoselección, consiguiendo que los coeficientes de la primera ecuación sean consistentes (Tabla 9).

TABla 9. Modelo de HeCKMAN (SEgundo parcial)

\begin{tabular}{|c|c|c|c|c|c|}
\hline \multirow[b]{2}{*}{ Variable } & \multicolumn{2}{|c|}{ Coeficientes no estandarizados } & \multirow[b]{2}{*}{ Coeficientes estandarizados } & \multicolumn{2}{|c|}{ Prueba $t$} \\
\hline & Beta & Error(Beta) & & Valor t & Signific. (p) \\
\hline 1PCAL & 0,793 & 0,060 & 0,720 & 6,326 & $0,000 * *$ \\
\hline EXPPAR & 1,460 & 0,623 & 0,146 & 1,771 & $0,003^{* *}$ \\
\hline Constante & $-2,553$ & 0,656 & & $-2,056$ & $0,000 * *$ \\
\hline $\begin{array}{l}R^{2}\left(R^{2} \text { ajustc }\right. \\
F(P) 113,82 \\
\text { Durbin Wat }\end{array}$ & $\begin{array}{l}\text { da) } 0,537(0 \\
7(0,000) \\
\text { son } 2,107\end{array}$ & & & & \\
\hline
\end{tabular}

Nota: ${ }^{*}$ significativo al $95 \%(p=0,05),{ }^{* *}$ significativo al $99 \%(p=0,01)$

Los resultados obtenidos indican que tanto la calificación del primer parcial $(p=0,000)$ como la participación en la experiencia $(p=0,003)$ constituyen variables estadísticamente significativas y explicativas de la calificación obtenida en el segundo parcial ( $R 2=0,537, F p=0,000)$. La aplicación del modelo de Heckman en dos etapas garantiza que los resultados obtenidos están libres del sesgo de autoselección, es decir, con independencia de las calificaciones obtenidas en el primer parcial, la participación en la experiencia incrementa la nota obtenida por el alumno en el segundo parcial de la asignatura. Este resultado confirma la validez de la experiencia y refuerza su aplicabilidad para el aprendizaje activo de la asignatura.

Por ultimo, se ha contrastado la relación existente entre la decisión de presentarse a la convocatoria oficial de la asignatura, la participación en la experiencia y la superación de las distintas pruebas realizadas durante el curso.

La relación entre la superación de los exámenes parciales y la presencia en la convocatoria es directa e inmediata: los alumnos que han superado todas las pruebas aparecen como aprobados en las actas de la asignatura. Asimismo, la superación de alguna prueba motiva al alumno a presentarse a recuperar las demás, con el objetivo de no perder la calificación obtenida.

Por lo que respecta a la participación en la experiencia, ésta no era obligatoria al tiempo que la calificación obtenida se mantenía durante otras dos convocatorias adicionales. No obstante, una experiencia exitosa debería motivar al alumno para aprovechar el trabajo realizado y las competencias adquiridas de forma inmediata, mediante su presentación en la correspondiente convocatoria. 
De esta forma, formulamos el siguiente conjunto de hipótesis, a contrastar mediante un modelo de análisis discriminante (Tabla 10):

$\mathrm{H}_{51}$ : Existe una relación directa entre la superación o no del primer parcial y la decisión de presentarse a la convocatoria de junio.

$\mathrm{H}_{52}$ : Existe una relación directa entre la superación o no del segundo parcial y la decisión de presentarse a la convocatoria de junio.

$\mathrm{H}_{53}$ : Existe una relación directa entre la participación o no en la experiencia y la decisión de presentarse a la convocatoria de junio.

Los resultados obtenidos permiten contrastar las hipótesis previas, siendo la superación del primer parcial la variable más explicativa de la decisión del alumno a presentarse a la convocatoria oficial de la asignatura (carga discriminante=0,849), seguida de la participación en la experiencia (carga discriminante=0,762), ello a pesar de no ser un requisito obligatorio para superar la asignatura. Asimismo, la superación del primer parcial afecta a la decisión del alumno, aunque en menor medida (carga discriminante $=0,554$ ), quizás debido a la menor nota media obtenida respecto al primer parcial. De nuevo, el número de matrículas y las convocatorias a las que se ha presentado el alumno no resultan significativas en la decisión de presentarse a la convocatoria analizada (carga discriminante $<0,05$ )

TABLA 10. ANÁLISIS DISCRIMINANTE (CONVOCATORIA FINAL)

\begin{tabular}{|c|c|c|c|c|c|}
\hline \multirow[t]{2}{*}{ Variable } & \multicolumn{2}{|c|}{ Coeficientes canonicos } & \multirow{2}{*}{$\begin{array}{c}\text { Carga } \\
\text { discriminante } \\
\text { (valor absoluto) }\end{array}$} & \multicolumn{2}{|c|}{$\begin{array}{c}\text { Coeficientes lineales de } \\
\text { Fisher }\end{array}$} \\
\hline & $\begin{array}{c}\text { No } \\
\text { estandarizados }\end{array}$ & Estandarizados & & $\begin{array}{c}\text { Grupo } 1 \\
\text { (PRPRES=0) }\end{array}$ & $\begin{array}{c}\text { Grupo } 1 \\
\text { (PRPRES=1) }\end{array}$ \\
\hline 1PSUP & 0,360 & 0,214 & 0,849 & 4,098 & 4,676 \\
\hline EXPPAR & 1,308 & 0,541 & 0,762 & 2,739 & 4,840 \\
\hline 2PSUP & 0,857 & 0,542 & 0,554 & $-1,561$ & $-0,185$ \\
\hline MATR & 0,116 & 0,172 & 0,041 & 1,436 & 1,621 \\
\hline CONV & 0,164 & 0,107 & 0,022 & $-0,341$ & $-0,077$ \\
\hline Constante & $-2,197$ & & & $-4,328$ & $-7,960$ \\
\hline \multicolumn{6}{|c|}{$\begin{array}{l}\text { Labmda de Wilks } 0,607 \\
\mathrm{Chi}^{2} \text { (p) } 109,416(0,000) \\
\mathrm{CCC}^{2} 0,393 \\
\text { Porcentaje correcto de clasificación (s.t.g) } 79,01 \% \\
\text { Criterio de aleatoriedad proporcional } 50,29 \%\end{array}$} \\
\hline
\end{tabular}

Los resultados obtenidos permiten contrastar las hipótesis previas, siendo la superación del primer parcial la variable más explicativa de la decisión del alumno a presentarse a la convocatoria oficial de la asignatura (carga discriminante=0,849), seguida de la participación en la experiencia (carga discriminante=0,762), ello a pesar de no ser un requisito obligatorio para superar la asignatura. Asimismo, la superación del primer parcial afecta a la decisión del alumno, aunque en menor medida (carga discriminante $=0,554$ ), quizás debido a la menor nota media obtenida respecto al primer parcial. De nuevo, el número de matrículas y las convocatorias a las que se ha presentado el alumno no resultan significativas en la decisión de presentarse a la convocatoria analizada (carga discriminante $<0,05$ )

Por ultimo, se analizó la relación existente entre la calificación numérica final del alumno en la convocatoria analizada, las notas obtenidas en los distintos parciales, y la participación en la experiencia, estableciéndose las siguientes hipótesis de trabajo:

$\mathrm{H}_{61}$ : Existe una relación directa entre la calificación del primer parcial y la calificación final obtenida. 
$\mathrm{H}_{62}$ : Existe una relación directa entre la calificación del segundo parcial y la calificación final obtenida.

H63: Existe una relación directa entre la participación o no en la experiencia y la calificación final obtenida.

La presencia de sesgo de autoselección ha llevado a estimar un nuevo modelo de Heckmann en dos etapas, como sigue: (1) la primera ecuación de regresión considera como variable dependiente la calificación final obtenida (0-10), y como variables independientes la calificación del primer y segundo parcial, y la participación en la experiencia; (2) la segunda ecuación corresponde a un modelo probit similar al definido respecto a la Tabla 9.

La Tabla 11 resume los resultados obtenidos para el modelo fundamental de regresión (ecuación 1 del modelo de Heckman).

TAbla 11. Modelo de Heckman (CONVOCATORIA final)

\begin{tabular}{|c|c|c|c|c|c|}
\hline \multirow[b]{2}{*}{ Variable } & \multicolumn{2}{|c|}{ Coeficientes no estandarizados } & \multirow[b]{2}{*}{ Coeficientes estandarizados } & \multicolumn{2}{|c|}{ Prueba t } \\
\hline & Beta & Error(Beta) & & Valor $t$ & Signific. (p) \\
\hline 1PCAL & 0,280 & 0,095 & 0,229 & 3,038 & $0,003^{* *}$ \\
\hline EXPPAR & 0,431 & 0,319 & 0,093 & 1,748 & $0,082^{+}$ \\
\hline 2PCAL & 0,689 & 0,090 & 0,538 & 7,683 & $0,000 * *$ \\
\hline Constante & $-0,388$ & 0,537 & & $-0,832$ & 0,407 \\
\hline $\begin{array}{l}R^{2}\left(R^{2} \text { ajustc }\right. \\
F(p) 72,056 \\
\text { Durbin Wat }\end{array}$ & $\begin{array}{l}\text { da) } 0,496(0, \\
(0,000) \\
\text { son } 2,164\end{array}$ & 489) & & & \\
\hline
\end{tabular}

Nota: ${ }^{+}$significativo al 90\% $(p=0,10),{ }^{*}$ significativo al 95\% $(p=0,05),{ }^{* *}$ significativo al $99 \%(p=0,01)$

Como cabía esperar, las calificaciones obtenidas en el primer y segundo parcial influyen de forma directa y positiva en la calificación final obtenida por el alumno, dado que aquellos alumnos que habían superado alguna de las pruebas parciales conservaban dicha calificación para la nota final. En particular, la capacidad explicativa de la segunda prueba es superior a la primera $(0,538$ vs. 0,229$)$, lo que resulta congruente con el modelo de aprendizaje incremental de la asignatura. Asimismo, la participación en la experiencia influye de forma directa y positiva en la calificación final, si bien su efecto es menor al encontrarse parcialmente recogido en la nota del segundo parcial (véase Tabla 9). En particular, los alumnos que realizaron el trabajo en grupo obtuvieron una calificación media entre 0,112 y 0,750 puntos superior a los estudiantes que no realizaron el trabajo (coeficientes no estandarizados: $0,431 \pm 0,319)$, lo que corrobora la validez del trabajo en grupo como un modelo de aprendizaje complementario a las pruebas ordinarias de evaluación.

\subsection{ResUltADOS PARA EL PROFESOR}

La realización de la experiencia evidenció una serie de resultados adicionales para el profesorado implicado en la misma, que se resumen a continuación. Mediante comunicación informal, todos los tutores mostraron su entusiasmo con la experiencia, indicando que ésta permitía a los alumnos aproximarse a la realidad empresarial de forma directa y autónoma, constituyendo un complemento valioso respecto a la formación proporcionada en las clases teóricas y prácticas de la asignatura. Asimismo, el trato profesor-alumno fue calificado de cordial y respetuoso.

No obstante lo anterior, los tutores detectaron un conjunto de problemas prácticos en la aplicación de la experiencia, entre los que destaca la tendencia de los alumnos a 
preguntar directamente al tutor ante cualquier duda de registro contable, en lugar de buscar autónomamente la posible solución, y luego contrastarla con el profesor. Ante esta disfunción, debida al tipo de aprendizaje tradicional del alumno, los tutores proporcionaron en todo caso a los alumnos las referencias básicas para la búsqueda de la solución necesaria, en lugar de la solución en sí misma.

Igualmente, los tutores observaron que la carga de trabajo real resultaba superior a la reducción en la carga docente asignada. A través de un pequeño cuestionario que recogía la hora de inicio y finalización de cada tutoría, se detectó que la media aproximada de tiempo dedicado por grupo fue de 33 minutos (primera tutoría) y 42 minutos (segunda tutoría), lo que supone un incremento del $15,51 \%$ y del $47,011 \%$ sobre el tiempo inicialmente asignado, respectivamente. Por su parte, la corrección y evaluación del trabajo no implicó grandes variaciones respecto al tiempo estimado (28 minutos), debido a que el seguimiento individualizado de cada grupo facilitó en gran medida dicha tarea. De esta forma, la carga real de trabajo de un tutor supuso un total de 1,8 créditos docentes frente a los 1,5 créditos asignados (Tabla 12).

TABla 12. Carga de trabajo para el Profesor

\begin{tabular}{|l|r|r|r|}
\hline & \multicolumn{1}{|c|}{ Tiempo estimado } & Tiempo real & \multicolumn{1}{c|}{ Diferencia } \\
\hline Primera tutoría & $28,57 \mathrm{~min}(\times 10,5=5 \mathrm{~h})$ & $33 \min (\times 10,5=5,78 \mathrm{~h})$ & $-4,43(\times 10,5=-0,78 \mathrm{~h})$ \\
\hline Segunda tutoría & $28,57 \mathrm{~min}(\times 10,5=5 \mathrm{~h})$ & $42 \min (\times 10,5=7,35 \mathrm{~h})$ & $-13,43(\times 10,5=-2,35 \mathrm{~h})$ \\
\hline Eval. y calificación & $28,57 \mathrm{~min}(\times 10,5=5 \mathrm{~h})$ & $28 \min (\times 10,5=4,90 \mathrm{~h})$ & $0,57(\times 10,5=0,10 \mathrm{~h})$ \\
\hline Suma & $\mathbf{1 5} \mathbf{h}(\mathbf{1 , 5}$ créditos $)$ & $\mathbf{1 8 , 0 3 h}(\mathbf{1 , 8}$ créditos $)$ & $\mathbf{- 3 , 0 2} \mathbf{h} \mathbf{( 0 , 3}$ créditos $)$ \\
\hline
\end{tabular}

Aunque los tutores afirmaron que su participación en la experiencia no se debía exclusivamente a la reducción en la carga docente sino a la convicción personal sobre su utilidad, sí confirmaron que la reducción lectiva incrementó su motivación y compromiso con la misma. De esta forma, los datos obtenidos deben considerarse especialmente de cara a la futura implantación de experiencias similares.

\section{CONCLUSIONES Y APLICACIÓN FUTURA}

El Espacio Europeo de Educación Superior pone de manifiesto la necesidad de incrementar el trabajo autónomo del estudiante, desarrollando competencias vinculadas al ejercicio de la práctica profesional y al aprendizaje a lo largo de la vida. Con este objetivo, en este trabajo se presenta una experiencia de innovación docente realizada en el ámbito de la asignatura de Contabilidad Financiera, basada en la realización de un trabajo en grupo centrado en el análisis y registro de documentación administrativo-contable. De esta forma, se pretende aproximar al alumno a la realidad empresarial, fomentando las habilidades vinculadas con la búsqueda de información, el análisis de datos, la discusión y trabajo en equipo, y la resolución dinámica de problemas.

Si bien la participación en la experiencia se planteó de forma voluntaria, la realización del trabajo ha demostrado ser determinante para la superación de la asignatura, debido a la calidad observada en los trabajos realizados. Los criterios de evaluación del trabajo tuvieron presente el desarrollo de un conjunto de competencias genéricas y específicas definidas previamente por el equipo docente (Anexo I, cuadro 3); si bien las competencias específicas pudieron medirse a través de los resultados obtenidos por los alumnos en las distintas pruebas de evaluación, las competencias genéricas no pudieron ser objeto de medición explícita. 
Los resultados obtenidos, una vez controlado el sesgo de autoselección, confirmaron el efecto positivo de la experiencia sobre las calificaciones del alumno y su implicación con la asignatura, aumentando significativamente los porcentajes de presentación y las calificaciones obtenidas respecto a los no partícipes (datos referentes al segundo parcial y convocatoria final). El efecto sobre la implicación se observó respecto a todos los alumnos que participaron en la experiencia, con independencia de que la superaran o no, dado que el porcentaje de no presentados se redujo al $36 \%$ y $22 \%$ (respectivamente) frente al $88 \%$ de los no partícipes. El efecto sobre las calificaciones se observó especialmente respecto a los alumnos que realizaron y superaron la experiencia (porcentaje de aprobados del 56\%), reduciéndose al $44 \%$ para aquellos que no superaron el trabajo, y siendo tan sólo del $4 \%$ para los no partícipes. Las cifras obtenidas permitieron observar un incremento del porcentaje final de aprobados respecto al obtenido en cursos anteriores.

Por su parte, el profesorado implicado calificó la experiencia como "muy positiva" en términos del aprendizaje del alumno y de la relación personal con los grupos de trabajo. Como principales inconvenientes, se observaron limitaciones respecto a la autonomía real de los alumnos, consecuencia de los esquemas tradicionales de aprendizaje seguidos hasta el momento, lo que resulta congruente con las conclusiones obtenidas por Arquero y Tejero (2011) quienes observan que los alumnos de contabilidad son más dependientes que los estudiantes de otras titulaciones. Asimismo, la carga de trabajo de los tutores superó la planificación realizada, lo que debe tenerse en cuenta de cara a su motivación y compromiso en el futuro. En particular, es necesario que el profesor disponga de un reconocimiento adecuado del esfuerzo realizado, bien mediante reducciones de la carga docente, bien mediante mecanismos alternativos, para potenciar el éxito en la generalización de este tipo de experiencias.

Los resultados obtenidos sugieren la idoneidad de la aplicación de esta experiencia en los nuevos estudios de Grado en Administración y Dirección de Empresas y Grado en Finanzas y Contabilidad. El contexto en los estudios de grado se asemeja más a la filosofía subyacente en esta experiencia, dado que prima el aprendizaje autónomo y el desarrollo de competencias, potenciando la evaluación continua sin necesidad de realizar exámenes finales que representen el 100\% de la calificación final. No obstante, también habría que considerar una serie de limitaciones de la experiencia planteada, tales como su voluntariedad (lo que introduce un sesgo en los resultados respecto a experiencias implantadas de forma obligatoria), o su cronograma (una vez que los alumnos han realizado las primeras pruebas de la asignatura, lo que sesga los resultados hacia los estudiantes más comprometidos).

En este caso, la implantación de la experiencia docente se recomienda para una asignatura semestral de Contabilidad Financiera de carácter intermedio, lo que permitiría al alumno no sólo aplicar los conocimientos básicos adquiridos en cursos previos, sino aplicar esquemas de aprendizaje autónomo desde el inicio del curso, que incrementen el compromiso del alumno y faciliten la adquisición de las competencias definidas para la materia. 


\section{BIBLIOGRAFÍA}

ARQUeRO MONTAÑO, J.L. (2000): Capacidades no técnicas en el perfil profesional en contabilidad: las opiniones de docentes y profesionales. Revista Española de Financiación y Contabilidad, XXIX(103): 149-172.

ARquero MONTAÑo, J.L., Donoso Anes, J.A., Jiménez CARdoso, S.M. y GonzÁlez González, J.M. (2009): Análisis exploratorio del perfil demandado para administración y dirección de empresas: implicaciones para el área contable. Revista de Contabilidad-Spanish Accounting Review, 12(2): 181-214.

ARquero MONTAÑo, J.L. Y TeJero RIOJA, C. (2011): How well adapted are accounting students for Bologna? A comparative analysis of learning styles of Spanish social sciences students. Revista de Educación en Contabilidad, Finanzas y Administración de Empresas, 2: 145-156.

ASHRAF, M. (2004): A critical look at the use of group projects as a pedagogical tool. Journal of Education for Business, 79(4): 213-216.

BROOKS, C.M. Y AMMONS, J.L. (2003): Free ridding in group projects and the effects of timing, frequency, and specificity of criteria in peer assessments. Journal of Education for Business, 78(5): 268-272.

CIDUA (2005): Informe sobre la innovación de la docencia en las universidades andaluzas. Comisión para la innovación de la docencia en las universidades andaluzas.

CONFEDE (Conferencia de Decanos de Facultades de Ciencias Económicas y Empresariales) (2005): Libro blanco sobre los estudios de grado en economía y en empresa.

GaIRIN, J.; FeIXAS, M., GuILlamÓN, C. Y DinQUer, D. (2004): La tutoría académica en el escenario europeo de Educación superior. Revista Interuniversitaria de Formación del Profesorado, 18(1): 66-77.

GonzÁleZ, J. Y WAGENAAR, R. (EDS.) (2003): Tuning Educational Structures in Europe. Informe Final. Fase Uno. Bilbao: Universidad de Deusto. Disponible en la página web del proyecto Tuning en la Universidad de Deusto: http://www.relint.deusto.es/TUNINGProject/spanish/doc2_fase1.asp (Fecha de Consulta: 22/12/2011).

Escobar Pérez, B. y Jiménez CARdoso S.M. (2009): La implantación del grado en finanzas y contabilidad en el contexto del espacio europeo de educación superior: el caso de la universidad de Sevilla. Revista Española de Financiación y Contabilidad, XXXVIII(142): 293-310.

HAIR, JR, J.F., ANDESON, RE., TATHAM, R.L. Y BLACK, W.C. (1999): Análisis Multivariante. Madrid: Prentice Hall.

Hassall, T., JOYCE, J., ARQUeRo, J.L. y DONOSO, J.A. (2005): Priorities for the development of vocational skills in management accountants: A European perspective, Accounting Forum, 29: 379-394.

HANSEN, R.S. (2006): Benefits and problems with student teams: suggestions for improving team Project. Journal of Education for Business, 82(1): 11-19.

HECKMAN, J.J. (1979): Sample Selection Bias as a Specification Error. Econometrica, 47(1): 153-161.

IFAC (2008): Manual de los Pronunciamientos Internacionales de Formación Edición 2008 (Spanish Translation). Nueva York: International Federation of Accountants (IFAC).

LASNIER, R. (2000) : Réussir la formation par compétences. Montréal: Guérin.

MCKENDALL, M. (2000): Teaching groups to become teams. Journal of Education for Business, 75(5): 277-282. 
MEC (2006a): Propuestas para la renovación de las metodologías educativas en la universidad. Ministerio de Educación y Ciencia, Secretaría de Estado de Universidad e Investigación.

MEC (2006b): Directrices para la elaboración de títulos universitarios de grado y máster. Documento de trabajo, 21 de diciembre, Ministerio de Educación y Ciencia, Secretaría de Estado de Universidad e Investigación.

RODRíGUeZ ESPINAR, S. (COORD.) (2004): Manual de tutoría universitaria. Recursos para la acción. Barcelona: Ediciones Octaedro.

SÁNCHEZ TOMÁs, A. (1991): Integración del ordenador y de la tecnología de la información en la enseñanza de la Contabilidad. Partida Doble, 15: 64-71.

YOUNG, C.B. Y HENQUINET, J.A. (2000): A conceptual framework for designing groups projects. Journal of Education for Business, 76(1): 56-60.

ZAPATA ROS, M. (1999): Internet y educación. Contextos de Educación, nº 2. Córdoba (Argentina): Universidad de Río Cuarto. 
Raquel Flórez, Esther Albelda

Una experiencia de trabajo en equipo para la formación de competencias

\section{ANEXO 1: Detalles del diseño de la experiencia}

Cuadro 1.Cronograma

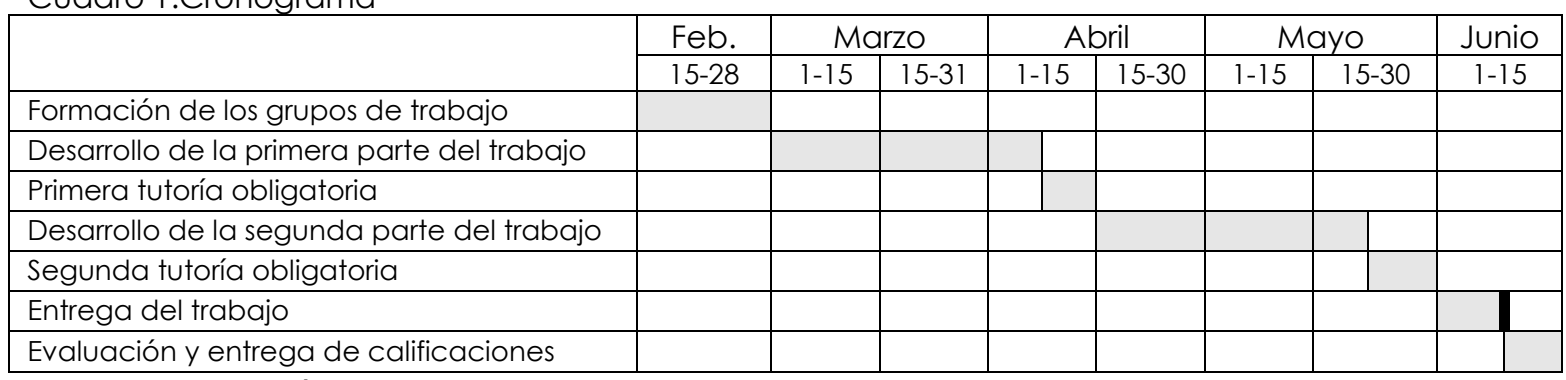

Fuente: Elaboración propia

Cuadro 2. Relación de documentos administrativos

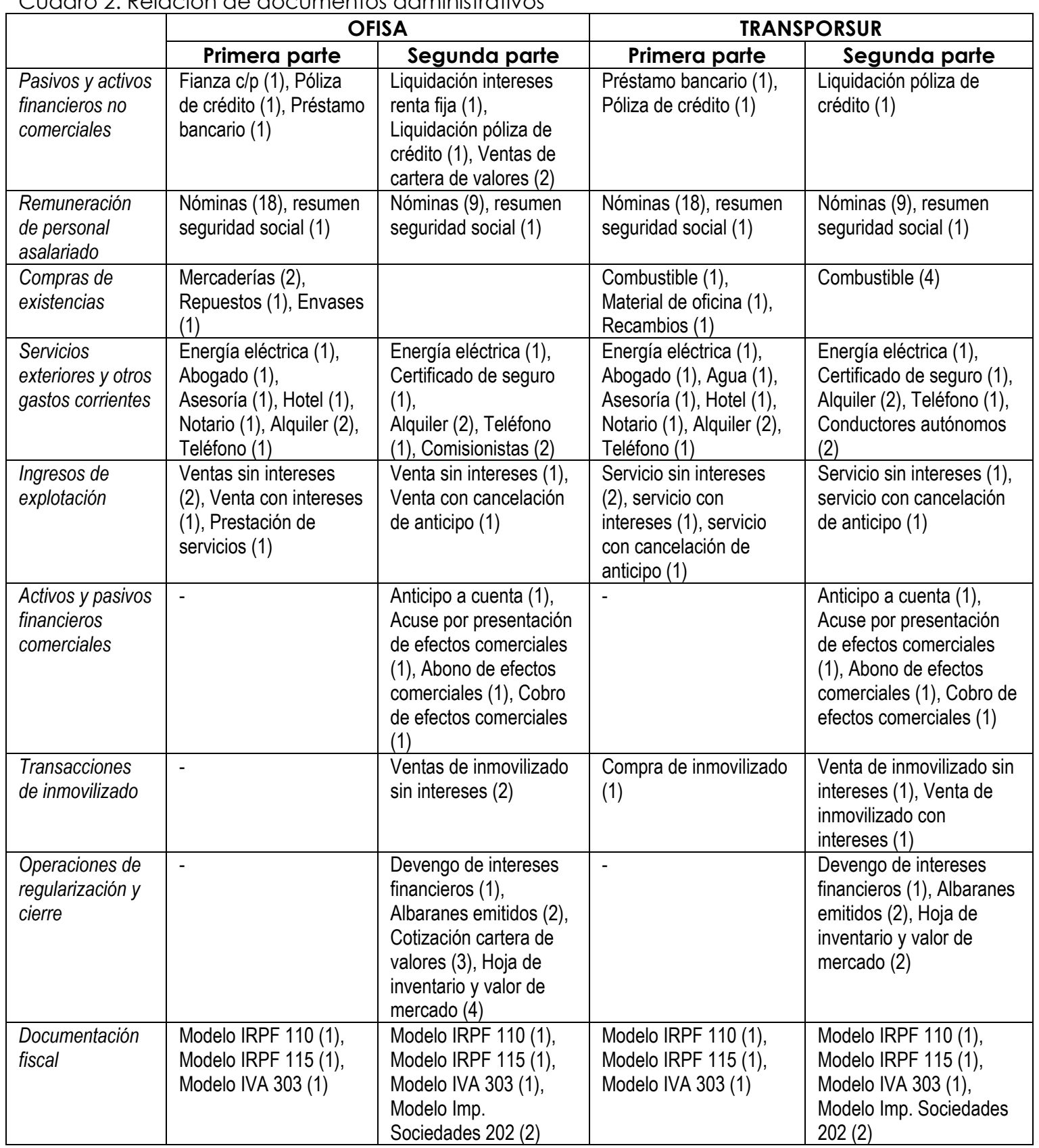


Cuadro 2. Relación de documentos administrativos (cont)

\begin{tabular}{|l|l|l|l|l|}
\hline $\begin{array}{l}\text { Documentación } \\
\text { social }\end{array}$ & $\begin{array}{l}\text { Modelos Seguridad } \\
\text { Social TC1 y TC2 (1) }\end{array}$ & $\begin{array}{l}\text { Modelos Seguridad } \\
\text { Social TC1 y TC2 (1) }\end{array}$ & $\begin{array}{l}\text { Modelos Seguridad } \\
\text { Social TC1 y TC2 (1) }\end{array}$ & $\begin{array}{l}\text { Modelos Seguridad Social } \\
\text { TC1 y TC2 (1) }\end{array}$ \\
\hline documentación & Contrato de alquiler (1), & - & Contrato de alquiler (1), & - \\
& Anexo de inmovilizado & & $\begin{array}{l}\text { Anexo de inmovilizado } \\
\text { (1), Cuadro de }\end{array}$ & \\
& (1), Cuadro de & & amortización préstamo & \\
& amortización préstamo & & (1), Contrato de crédito & \\
& (1), Contrato de crédito & & & \\
& en cuenta corriente (1) & \\
& Cartera de valores (3) & & & \\
\hline
\end{tabular}

Fuente: Elaboración propia

Cuadro 3. Hoja de Evaluación

\begin{tabular}{|c|c|c|c|c|c|c|}
\hline \multicolumn{7}{|c|}{ HOJA DE EVALUACIÓN DEL TRABAJO EN EQUIPO CON SOPORTE DOCUMENTAL } \\
\hline Actividad & Factores & Descripción & $\begin{array}{l}\text { Comp. } \\
\text { genéricas } \\
\text { relacionadas }\end{array}$ & $\begin{array}{l}\text { Comp. } \\
\text { específicas } \\
\text { relacionadas }\end{array}$ & $\begin{array}{l}\text { Punt. } \\
\text { Máx. }\end{array}$ & $\begin{array}{c}\text { Punt. } \\
\text { Obtenida }\end{array}$ \\
\hline $\begin{array}{c}1^{a} \\
\text { tutoría }\end{array}$ & $\begin{array}{l}\text { Planteamiento } \\
\text { del trabajo }\left(3^{\circ}\right. \\
\text { trimestre) }\end{array}$ & $\begin{array}{l}\text { Nivel de avance (identificación } \\
\text { de elementos, comprensión de } \\
\text { la tarea a realizar, dudas } \\
\text { planteadas...) }\end{array}$ & $\begin{array}{l}(1),(2),(3), \\
(4), 15\end{array}$ & (7), (8), (9) & 1 & \\
\hline $\begin{array}{c}2^{a} \\
\text { tutoría }\end{array}$ & $\begin{array}{l}\text { Seguimiento } \\
\text { del trabajo ( } 4^{\circ} \\
\text { trimestre) }\end{array}$ & $\begin{array}{l}\text { Nivel de avance (corrección de } \\
\text { los errores anteriores, adelanto } \\
\text { del trabajo, dudas planteadas...) }\end{array}$ & $\begin{array}{l}(1),(2),(3) \\
(4), 15\end{array}$ & (7), (8), (9) & 1 & \\
\hline \multirow[t]{2}{*}{$\begin{array}{l}\text { Trabajo } \\
\text { final }\end{array}$} & $\begin{array}{l}\text { Aspectos } \\
\text { formales }\end{array}$ & $\begin{array}{l}\text { Presentación: orden, limpieza, } \\
\text { identificación de sus } \\
\text { componentes y profesor } \\
\text { responsable }(0,25) \\
\text { Redacción: gramática y } \\
\text { ortografía, claridad, coherencia, } \\
\text { leguaje adecuado }(0,25) \\
\text { Cumplimiento de los requisitos } \\
\text { establecidos: tarea completa } \\
\text { adjuntando toda la } \\
\text { documentación solicitada }(0,25) \\
\text { Organización electrónica de la } \\
\text { información (hoja de cálculo) } \\
(0,25)\end{array}$ & $\begin{array}{l}(1),(3),(4), \\
(6)\end{array}$ & (9) & 1 & \\
\hline & $\begin{array}{l}\text { Contenido del } \\
\text { trabajo }\end{array}$ & $\begin{array}{l}\text { Contabilización de las } \\
\text { operaciones del } 3^{\circ} \text { trimestre }(1,5) \\
\text { Contabilización de las } \\
\text { operaciones del } 4^{\circ} \text { trimestre }(1,5) \\
\text { Cálculo del resultado del } \\
\text { ejercicio y cierre }(1,5) \\
\text { Elaboración de modelos } \\
\text { administrativos }(1,5) \\
\text { Justificación teórica y } \\
\text { explicaciones de las } \\
\text { operaciones contabilizadas }(1)\end{array}$ & $\begin{array}{l}(1),(3),(5), \\
(6)\end{array}$ & (7), (8), (9) & 7 & \\
\hline \multicolumn{5}{|c|}{ ( } & & 10 \\
\hline \multicolumn{2}{|c|}{ Factor corrector } & $\begin{array}{l}\text { Participación en tutorías de } \\
\text { seguimiento } \\
\text { Asistencia a tutorías voluntarias } \\
\text { Implicación/cohesión del grupo }\end{array}$ & $\begin{array}{l}(1),(2),(3), \\
(5)\end{array}$ & (7) & \multicolumn{2}{|c|}{$+/-2$} \\
\hline
\end{tabular}

Fuente: Elaboración propia 